Purdue University Purdue e-Pubs

$1-1-2010$

\title{
Hedging Price Volatility Using Fast Transport
}

David L. Hummels

Purdue University

Georg Schaur

The University of Tennessee, Knoxville

Follow this and additional works at: http://docs.lib.purdue.edu/ciberwp

Hummels, David L. and Schaur, Georg, "Hedging Price Volatility Using Fast Transport" (2010). Purdue CIBER Working Papers. Paper 64.

http://docs.lib.purdue.edu/ciberwp/64

This document has been made available through Purdue e-Pubs, a service of the Purdue University Libraries. Please contact epubs@purdue.edu for additional information. 
Businesses Educarionand Research

\section{Hedging Price Volatility Using Fast Transport}

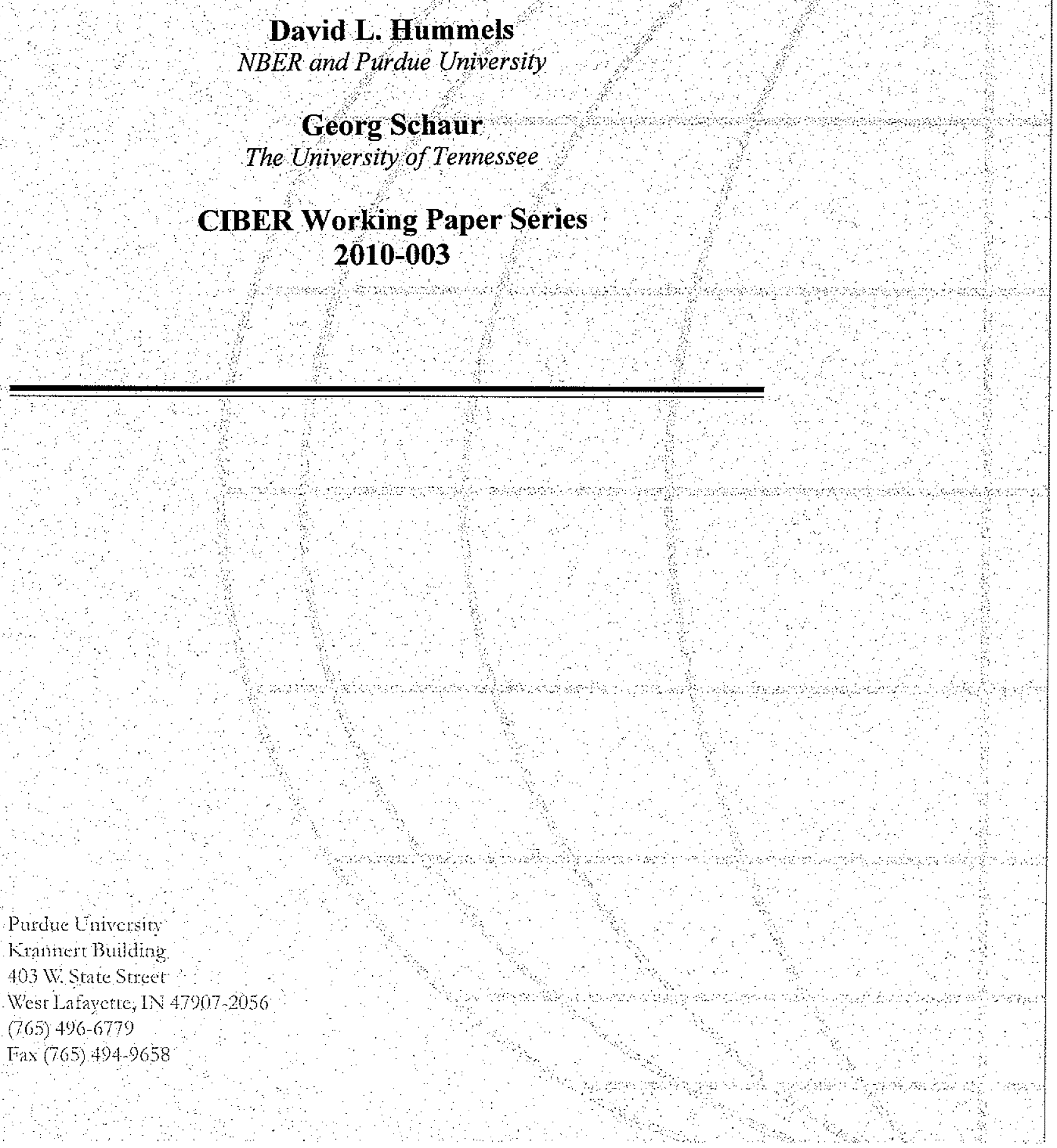




\title{
Hedging Price Volatility Using Fast Transport th
}

\author{
David L. Hummels*,a, Georg Schaur**b \\ ${ }^{a}$ NBER and Purdue University, West Lafayette, USA \\ ${ }^{b}$ The University of Tennessee, Knoxville, USA
}

Abstract

Purchasing goods from distant locations introduces a significant lag between when a product is shipped and when it arrives. These transit lags are trade barriers for firms facing volatile demand, who must place orders before knowing the resolution of demand uncertainty. We provide a model in which airplanes bring producers and consumers together in time. Fast transport allows firms to respond quickly to favorable demand realizations and to limit the risk of unprofitably large quantities during low demand periods. The model predicts that the likelihood and extent to which firms employ air shipments is increasing in the volatility of demand they face, decreasing in the air premium they must pay, and increasing in the contemporaneous realization of demand. We confirm all three conjectures using detailed US import data. Fast transport thus provides firms with a real option to smooth demand volatility on international markets, and we provide simple calculations of that option value. This enables us to identify how the option value relates to goods characteristics, and to changes in air transport premia associated with technological and policy change including the introduction of jet engines, and liberalization of trade in air services.

Key words: Hedging; Volatility; Adjustment Costs; Air transport; Real Option JEL Codes: F1; F31; F36, F41; L91

\footnotetext{
We thank editor Bruce Blonigen and two anonymous referees for many helpful comments and suggestions on this draft. We also thank Jason Abrevaya, Jack Barron, Donald Davis, Kanda Naknoi, Chong Xiang, Adina Ardelean, Vova Lugovskyy, participants at the EIIT 2006, Midwest Meetings Fall 2007, 10th Annual GTAP Conference and seminar participants at Purdue University, The University of Tennessee, UC Santa Cruz, Kansas State and Kent State. Any remaining errors are our own.

*Department of Economics, Rawls Hall, West Lafayette, IN 47907-1310.

** Corresponding author: Department of Economics, 505A Stokely Management Center, Knoxville, TN 37996-0550, Phone: 865-974-1710.

Email addresses: hummelsd@purdue.edu (David L. Hummels), gschaur@utk.edu (Georg Schaur) $U R L$ : www.mgmt . purdue.edu/faculty/hummelsd (David L. Hummels), http://econ.bus.utk.edu/schaur.html (Georg Schaur)
} 


\section{Introduction}

Firms facing volatile demand would like to respond ex-post to shocks by re-optimizing prices charged and quantities sold. However, when firms are separated from their consumers by long distances the lag between shipment and arrival can impose an important constraint on adjustment. For example, ocean-borne shipments from China require, on average, 24 days to reach the US market and many exporting countries face considerably longer shipping times. ${ }^{1}$ In a market with volatile demand, quantities shipped well in advance of the sales date may not maximize profits by the time they arrive.

In two recent papers James Harrigan and coauthors have argued that geographical proximity between suppliers and customers allows firms to respond to demand uncertainty. In a domestic context, the need for timeliness and short reaction times may drive up- and down-stream firms to cluster geographically (Harrigan and Venables, 2006). Internationally, firms may prefer to buy from nearby exporters in order to gain flexibility in the face of demand shocks even if this requires the payment of higher input costs (Evans and Harrigan, 2005). ${ }^{2}$

This paper explores an alternative solution available to firms facing volatile demand first suggested by Aizenman (2004). Rather than bringing production closer to consumers in space, airplanes bring production closer to consumers in time. Because air shipments can reach any destination in a day, firms can wait until uncertainty is resolved before deciding on quantities to be sold. As a consequence, air shipping provides firms with a real option to smooth demand shocks. Of course, air cargo commands a large premium relative to slower ocean cargo, which implies that adjusting quantities at the margin is subject to sharply higher costs. In US imports, costs per kg shipped are on average 5.7 times higher for air shipment (see Table 1).

Despite this premium, air shipment is widely employed in trade. Air cargo in 2000 represented 36 percent of US imports by value and 58 percent of US exports by value with partners outside North America. ${ }^{3}$ This is not simply a case of bulky

\footnotetext{
${ }^{1}$ The trade-weighted average of shipping times for all exporters to the US in 1999 was 22 days (www.shipguide.com). Data from 2006 show no significant change in ocean delivery speed.

${ }^{2}$ Fisher and Raman (1996) also focus on a quick response time in the apparel industry. Initial sales improve forecast accuracy to re-optimize supply. They do not consider implications for the location of production, input costs or tariff reductions.

${ }^{3}$ See Hummels (2007). Nor is the US anomalous: high income countries in Europe and Latin
} 
products arriving on boats and high value electronics arriving on planes. Rather, a substantial fraction of products arrive via a mixture of air and ocean modes. Denote an observation as an exporter selling an HS10 product (roughly 15,000 unique goods) in a year. Considering all US imports 1990-2004 from outside North America, 35 percent of observations representing 71 percent of trade by value enter the US through a mix of modes. Figure 1 provides a histogram of air shares for these observations and shows that mixing occurs across a broad range of product types with a continuously varying share of air shipment.

We examine theoretically and estimate empirically the extent to which air shipping allows firms to hedge price uncertainty on international markets. We model an exporter facing uncertain demand in a foreign market and a choice of serving that market using slow but inexpensive ocean transport or fast, expensive air transport. ${ }^{4}$ In order to arrive on time ocean shipments must depart prior to the resolution of a demand shock, while air shipments can be delayed until after the shock is realized. This enables the exporter to use an option strategy, sending an initial ocean shipment and then if the shock is sufficiently favorable, providing additional quantities via air.

Using only ocean shipping minimizes the total shipping bill, but incurs risk. If the realization of the shock is unfavorable, the exporter will have too much quantity on the market. Air shipments, on the other hand, optimize the quantity on the market, but at much higher cost. This tradeoff provides us with three empirical hypotheses. A high relative price for air shipping means that the real option of air transport is expensive and less likely to be used. A history of greater demand volatility will lead an exporter to reduce the initial ocean shipment and increases the likelihood that an air shipment will be observed. Finally, a high ex-post realization of demand will result in more air shipping in that period.

We examine these three predictions using 10 digit (HS) US Imports of Merchan-

\footnotetext{
America have similarly high air cargo shares in trade.

${ }^{4}$ There are subtle differences between our model and Aizenman's. In his model, the marginal cost of supply denominated in the consumer's currency is uncertain and consumers in the importing country can decide to increase quantities at the last minute given a favorable shock. In our model demand is uncertain and a monopolist decides whether to increase quantities given a favorable shock. Both models predict that air shipping is increasing in market volatility and decreasing in the cost of exercising the option. They differ in whether air shipments are called forth by low realizations of prices (favorable to consumers) or high realization of prices (favorable to firms).
} 
dise Data at monthly frequencies between 1990 and 2004. For each exporter-product observation we have data on trade quantities, prices, transport modes and transportation prices. Our dependent variables are, one, whether firms are employing an option strategy (mixing air and ocean), and two, the share of air shipments in total quantities. Looking across exporters and products there is considerable variation in the cost of exercising the air shipment option (the price of air relative to ocean shipping), and in the benefits of exercising that option (the history of demand volatility, and the contemporaneous realization of demand). We find that a history of greater demand volatility is positively related both to the likelihood that the option strategy is employed as well as the share of trade that is air shipped. Lower air freight rates, higher ocean freight rates, and a higher contemporaneous realization of demand lead to a larger share of air shipment.

This paper is related to several distinct literatures. First, we add to the literature on how demand uncertainty affects specialization. Like Evans and Harrigan (2005), who focus on retail restocking rates in the apparel industry, we show that demand volatility affects sourcing decisions. Unlike them, we examine trade in all products, and focus on how modal choice rather than choice of sourcing country can be used to smooth volatility. In short, we show that distance is a less significant penalty if low priced rapid transport is available.

Second, we provide the first empirical evidence for a tradeoff between uncertainty and time dependent transportation costs first suggested by the model in Aizenman (2004). Aizenman is primarily interested in the macroeconomic implications of this tradeoff. In particular, his model shows that the extent of exchange rate pass through is increasing in the share of last minute (air-borne) shipments. While we are interested in a more general set of demand shocks, Aizenman's paper makes clear that our findings have implications for the observed degree of exchange rate pass through.

Third, air shipping is widely used in international trade despite being much more expensive than ocean shipping. Hummels and Schaur (2009) show that exporters have a willingness to pay for faster shipping that far exceeds inventory holding costs. Using data on air versus ocean modal usage, they show that exporters will pay as much as $0.8 \%$ ad valorem to save a day in transit, but do not identify the precise source of this 
willingness-to-pay. This paper shows that the ability to hedge demand uncertainty with an appropriate transport mix is valuable, and that for exporters subject to high price volatility, the gains from smoothing risk cover the higher expense of air transport. To the extent that firms also use rapid shipping in a domestic context - air freight shipments within the US were valued at $\$ 770$ billion in 2002 - one can think about our results as evidence for an adjustment mechanism widely-employed by firms subject to demand shocks.

Finally, we can use our estimates along with a simplified version of the model to calculate the expected return on a hedging strategy. The expected return depends on the volatility of demand and the price of air transport, which varies significantly over time due to technological change, across goods due to their characteristics, and across countries due to policies such as open skies agreements that liberalize air cargo trade $^{5}$. The calculations imply goods with demand volatility one standard deviation above the mean have an option value 17.1 percent higher than the mean volatility good. Liberalizing trade in air cargo services raises the option value of air transport by about 17.02 percent. The introduction of jet engines raised the option value of air transport 30-fold for US imports and 100-fold for US exports. This suggests that de-regulation and technological change have sizable and important welfare consequences beyond the direct impact of lower input costs.

Section 2 contains our model of the firm's choice of air and ocean shipment in the face of demand uncertainty. Section 3 discusses the data and tests our three empirical predictions. Section 4 provides back of the envelope calculations of the option value of rapid transport. Section 5 concludes.

\section{Model}

Consider a monopolist that lives for two periods and produces a single good for the foreign market subject to uncertain demand. The inverse demand in the buyer's currency is given by $p=\epsilon(a-b Q)$, where $Q$ is the total quantity sold. ${ }^{6} \epsilon$ is a uniformly

\footnotetext{
${ }^{5}$ See Gordon (1990) for "new goods" estimates of the value of jet engines, Hummels (2007) for data on air cargo costs and the impact of technology and oil prices over time, and Micco and Serebrisky (2006) for the impact of open skies agreements on cross-country differences in cargo rates.

${ }^{6}$ Unlike Aizenman (2004), we abstract here from having distinct supplier and consumer currencies, and consider $\epsilon$ as representing any demand shock. However, $\epsilon$ could be interpreted as the value of
} 
distributed shock over the interval $(1-z, 1+z)$, with $1-z>0$ and $z \geq 0$ so that the price is strictly positive. ${ }^{7}$ In the first period the firm knows the distribution of $\epsilon$, but not its realization. The foreign market is active only in the second period during which demand shocks are realized. We abstract from inventory holding after the second period so that the firm sells all of $Q$ available on the market in this second period. ${ }^{8}$

The firm can produce and ship goods to the foreign market using a combination of ocean and air shipment. Let the quantity shipped over the ocean and air be $q^{o}$ and $q^{a}, Q=q^{o}+q^{a}$. Ocean shipment takes one period to arrive while air shipment arrives immediately. Given this timing, ocean quantities must be set before demand uncertainty is resolved while air quantities are decided after the demand shock is realized. The rates $f^{a}$ and $f^{o}$ determine the constant marginal cost of producing and then shipping a unit via air and ocean transport, $f^{a}>f^{o}$. This implies that shipping supply is perfectly elastic and exogenous to the firm. ${ }^{9}$ This gives the firm an option to rapidly adjust quantities on the market by paying a higher cost for air shipment.

The firm's problem is to determine the total quantity sold along with an optimal mix of ocean and air shipment. Without uncertainty, the exporter would ship the entire quantity via ocean to minimize the transport bill. With uncertainty, a larger ocean shipment increases the expected loss in the event of a bad demand shock. Waiting until the uncertainty is resolved allows the firm to optimize the total quantity on the market, but necessitates the use of more expensive air transport. The exporter balances the tradeoff between uncertainty and transportation cost to determine an optimal mix of air and ocean shipping.

To solve the exporter's problem we work backwards from the second period. We

the exchange rate. In this case freight rates would be denominated in the seller's currency, and fast transport would be used to hedge exchange rate risk.

${ }^{7}$ We employ linear demand and a uniformly distributed shock in the main text as it simplifies the analysis and allows for analytical solutions to the problem. In a theory appendix we show that the main results go through for a very general demand system with a multiplicative demand shock that is arbitrarily distributed, subject only to the assumption that prices are strictly positive.

${ }^{8}$ Baumol and Vinod (1970) take an inventory theoretic approach to the transport choice and safety stocks serve demand fluctuations. Our empirics support the transport mix as a relevant margin to smooth uncertainty. Safety stocks are in the alternative.

${ }^{9}$ The simplest interpretation is that marginal costs of production are the same for both transport modes so that the difference in rates represents only shipping costs. In this case, our empirical values for the rates exactly correspond to the theory. The theory is more general, in that the difference in rates can also be interpreted to include higher marginal costs of production for last minute sales. However, our data do not allow us to identify the production component of differential costs. 
first derive the exporter's optimal rule for air shipment as a function of the first-period ocean shipment and the realization of demand. We then employ this rule to derive the exporter's first-period expected profits and maximize expected profits to find the optimal ocean quantity.

The exporter calculates the second-period profit as total revenue minus costs,

$$
\pi_{2}=\epsilon\left(a-b\left(q^{o}+q^{a}\right)\right)\left(q^{o}+q^{a}\right)-q^{a} f^{a}-q^{o} f^{o} .
$$

Taking the ocean shipment $q^{o}$ and demand realization $\epsilon$ as given, the second period objective is to maximize the profit with respect to the air quantity $q^{a}$ subject to $q^{a} \geq 0$. (The firm cannot take quantities off the market or store them for subsequent periods.) Taking the derivative of $\pi_{2}$ with respect to $q^{a}$ yields the first order condition

$$
\frac{\partial \pi_{2}}{\partial q^{a}}=\epsilon\left(a-b q^{o}-b q^{a}\right)-\epsilon b\left(q^{o}+q^{a}\right)-f^{a}+\lambda=0
$$

where $\lambda$ is the La Grange multiplier on the constrained $q^{a} \geq 0$. For an interior optimum, the optimal air shipment is strictly greater than zero, $\lambda=0$, and marginal revenue of shipping an additional marginal unit by airplane must equal the marginal cost. ${ }^{10}$ From equation (2) solve for the optimal air shipment conditional on $q^{a}>0$,

$$
q^{a}=\frac{\epsilon a-f^{a}}{2 \epsilon b}-q^{o}
$$

To find the threshold value, $\epsilon^{*}$, that triggers an air shipment, set $q^{a}=0$ and solve for

$$
\epsilon^{*}=\frac{f^{a}}{a-2 b q^{\circ}}
$$

Combining these equations gives us the the optimal rule for air shipping

$$
q^{a}= \begin{cases}\frac{\epsilon a-f^{a}}{2 \epsilon b}-q^{o} & \text { if } \epsilon>\epsilon^{*} \\ 0 & \text { if } \epsilon \leq \epsilon^{*}\end{cases}
$$

Below $\epsilon^{*}$ the firm relies only on ocean shipments. Above $\epsilon^{*}$, air quantities are increasing

\footnotetext{
${ }^{10}$ For $b>0$, the second order condition, $\frac{\partial^{2} \pi_{2}}{\partial\left(q^{a}\right)^{2}}=-2 b<0$, is strictly negative for all $q^{a}$.
} 
in $\epsilon$ and decreasing in $f^{a}$ as the firm balances the higher marginal revenues from a greater realization of demand against the higher marginal cost of air shipment. The threshold value itself is increasing in the cost of air shipping and in the first-period ocean shipment. With a large quantity already on the market, additional air shipments will only be employed for higher realized values of demand.

Given the optimal rule for air shipping, we now solve for the optimal ocean quantity chosen in the first period. Substituting (5) into the second-period profit function (1) we obtain

$$
\pi_{2}\left(q^{o}\right)= \begin{cases}-q^{o} f^{o}-f^{a}\left(-q^{o}+\frac{a \epsilon-f^{a}}{2 b \epsilon}\right)+\epsilon\left(a-b \frac{a \epsilon-f^{a}}{2 b \epsilon}\right) \frac{\left(a \epsilon-f^{a}\right)}{2 b \epsilon} & \text { if } \epsilon>\epsilon^{*} \\ -q^{o} f^{o}+q^{o}\left(a-b q^{o}\right) \epsilon & \text { if } \epsilon \leq \epsilon^{*}\end{cases}
$$

For $\epsilon>\epsilon^{*}$, the firm's profits incorporate positive air and ocean quantities. For $\epsilon \leq \epsilon^{*}$, the firm sets $q^{a}=0$ and calculates the expected profit from the revenue and cost generated by the ocean quantity. Apply the density function of the uniform demand distribution, $d(\epsilon)=\frac{1}{2 z}$, and take the expectation over all possible realizations of the shock to derive the first-period expected profit function

$$
\begin{aligned}
E(\Pi)=- & q^{o} f^{o}+\int_{1-z}^{\epsilon^{*}}\left[q^{o}\left(a-b q^{o}\right) \epsilon\right] \frac{1}{2 z} d \epsilon \\
& +\int_{\epsilon^{*}}^{1+z}\left[-f^{a}\left(-q^{o}+\frac{a \epsilon-f^{a}}{2 b \epsilon}\right)+\epsilon\left[a-b \frac{a \epsilon-f^{a}}{2 b \epsilon}\right] \frac{\left(a \epsilon-f^{a}\right)}{2 b \epsilon}\right] \frac{1}{2 z} d \epsilon .
\end{aligned}
$$

Note that the bound of the integral $\epsilon^{*}$ is a function of the ocean quantity. We differentiate the expected profit $(7)$ with respect to $q^{o}$ to solve for the optimal ocean quantity as a function of the risk parameter $(z)$, unit air and ocean freight rates $\left(f^{a}\right.$ and $f^{o}$ ), as well as the demand parameters ( $a$ and $b$ )

$$
\begin{aligned}
q^{o} & =\frac{1}{2 b\left(1-2 z+z^{2}\right)} \times\left[-2 z a-f^{a} z+a-f^{a}+2 f^{o} z+z^{2} a\right. \\
& \left.+2 \sqrt{-f^{a} f^{o} z^{2}-f^{a} f^{o} z+\left(f^{o} z\right)^{2}+\left(f^{a}\right)^{2} z}\right] .
\end{aligned}
$$


The optimal ocean quantity, set in the first period, is affected by the cost of air shipping even in cases where the optimal air shipment in the second period may be zero. ${ }^{11}$ The reason is that the firm factors the possibility of bringing additional air quantities onto the market when setting initial ocean quantities. Substituting (8) into (3) and (4) we derive an analytical solution for the zero air shipment threshold and optimal air quantity for $\epsilon>\epsilon^{*}$ as a function of exogenous parameters.

$$
\begin{gathered}
\epsilon^{*}=f^{a} \frac{(1-z)^{2}}{f^{a} z+f^{a}-2 f^{o} z-2 \sqrt{\left(f^{o}-f^{a}\right) z\left(f^{a}-f^{o} z\right)}} . \\
q^{a}=\frac{\epsilon a-f^{a}}{2 \epsilon b}-\frac{1}{2 b\left(1-2 z+z^{2}\right)} \times\left[-2 z a-f^{a} z+a-f^{a}+2 f^{o} z+z^{2} a\right. \\
\left.+2 \sqrt{-f^{a} f^{o} z^{2}-f^{a} f^{o} z+\left(f^{o} z\right)^{2}+\left(f^{a}\right)^{2} z}\right]
\end{gathered}
$$

These are complex expressions and so we employ simulations to build intuition. Figure 2 describes regions of parameter space in which only ocean or a mix of air and ocean shipments are employed. It plots the air shipment threshold (solid line) for given values of the volatility parameter $z$ and realizations of the demand shock $\epsilon$, fixing other variables. For a level of demand volatility, $z^{\prime}, \epsilon$ is uniformly distributed on the support $\left[1-z^{\prime}, 1+z^{\prime}\right]$. The cone formed by dotted lines then shows the range $\left(2 z^{\prime}\right)$ of possible demand realizations at each level of volatility $z^{\prime}$. The range and the variance of $\epsilon$, $\sigma^{2}=\frac{1}{3} z^{2}$, are increasing in $z$.

Initially consider levels of volatility $z>z^{*}$. In this range the zero air shipment threshold lies within the cone. This means there is some realization of the demand shock that will cause the firm to bring additional quantities to market at higher cost. Since the demand shocks are uniformly distributed the ex-ante probability that air shipment is chosen is given by $\left(1+z-\epsilon^{*}\right) / 2 z$. The numerator corresponds to the shaded area in Figure 2, and the denominator corresponds to the width of the cone at a given level of volatility.

\footnotetext{
${ }^{11}$ The optimal ocean quantity satisfies the second order condition for the parameter values we consider in the following simulations.
} 
The ex-ante probability that air shipment is chosen is increasing in the volatility $z$. To see why, recall that the ocean quantity chosen in the first period depends on the volatility. When a firm faces a highly volatile market, the possibility exists that a demand shock well below $E(\epsilon)$ could be realized. This causes the firm to lower the first period ocean shipment, and delay shipping additional quantities until the uncertainty concludes. Lowering the ocean quantity in turn raises the marginal revenue of air shipping and makes it more likely that air shipment will be employed if demand shocks close to $E(\epsilon)$ are realized. To see this in Figure 2, suppose we fix the realization of the shock at its expected value $\epsilon=1$. Within the cone, the air shipment threshold is decreasing in $\mathrm{z}$ and crosses $\epsilon=1$ at $z=.45$. For levels of volatility $z<.45$, a demand realization $\epsilon=1$ will not call forth air shipment, whereas for volatility $z>.45$, that same demand realization will result in additional air shipments.

Of course, how much quantity the firm holds off the market in the first period depends on the relative cost of waiting. For a fixed level of demand volatility, a large first-period ocean shipment minimizes transport costs, but sacrifices flexibility to intervene on the market with an air shipment. As air shipping costs drop relative to ocean shipping, the air threshold shifts downwards, making air shipment more likely for all values of $\mathrm{z}$ and $\epsilon$. On the limit as $f^{a}$ approaches $f^{o}$, the firm no longer pays a premium for flexibility. It lowers ocean shipments to equal the quantity shipped under the worst possible demand realization, and serves any demand above this minimum using air shipment. As air shipping becomes very expensive, higher initial ocean quantities are chosen and the zero air threshold shifts upward for all levels of volatility.

Next, consider levels of volatility $z<z^{*}$ so that the air threshold lies outside the cone. In this region, realized demands cannot be much lower than expected demands and this raises initial ocean quantities. Combining high $q^{o}$ with a low demand ceiling (given our symmetric demand distribution $\epsilon$ can also not be much higher than $E(\epsilon)$ ), the firm will not choose air shipments for any feasible demand realization in this region. Knowing that air shipment will never be chosen, the firm's problem simplifies greatly. The firm constrains itself to $q^{a}=0$, and a profit maximizing ocean quantity is chosen as if the firm knew $E(\epsilon)=1$ with certainty.

Thus far we have focused on the likelihood that the firm chooses some positive 
quantity of air shipment in response to demand shocks. We can also calculate the expost share of air shipments and the expected share of demand served by late arriving shipments. For $q^{a}>0$, apply equation (5) to obtain the ex-post air share as a function of the demand shock

$$
\frac{q^{a}}{q^{a}+q^{o}}=\frac{\epsilon a-f^{a}-2 q^{o} \epsilon b}{\epsilon a-f^{a}}
$$

Recall that ocean quantities are set in the first period as a function of volatility and freight rates, given by equation (8). For given ocean quantities, a higher contemporaneous realization of demand $\epsilon$ increases the share of air shipments in the total quantity. Figure 3 shows how total quantities and prices vary with $\epsilon$, holding $z, f^{a}, f^{o}$ fixed. For $\epsilon<\epsilon^{*}$, the air share is zero, quantities are unresponsive to increases in demand, and $\partial \ln (p) / \partial \ln (\epsilon)=1$. For $\epsilon>\epsilon^{*}$, additional air quantities and the air share of shipments are rising in $\epsilon$, and $\partial \ln (p) / \partial \ln (\epsilon)<1$.

Taking expectations on the ex-post air share over all $\epsilon$, we obtain the expected share of air shipment averaged over all possible realizations of the shock,

$$
E\left(\frac{q^{a}}{q^{a}+q^{o}} \mid z, f^{a}, f^{o}, a, b, \gamma\right)=\int_{\frac{f^{a}}{a-2 b q^{o}(\cdot)}}^{\gamma+z} \frac{\epsilon a-f^{a}-2 q^{o}(\cdot) \epsilon b}{\epsilon a-f^{a}} \frac{1}{2 z} d \epsilon
$$

where $q^{o}(\cdot)$ is the optimal ocean quantity from equation (8). This is complex to evaluate given that $q^{o}(\cdot)$ determines the bound of the integral, so we again use simulation.

Figure 4 displays the expected share of air shipment over different levels of volatility facing the firm. For sufficiently high volatility $\left(z>z^{*}\right.$ as in Figure 2), the expected air shipment is increasing in the volatility. Raising the cost of the air shipping option (the dotted line) lowers expected air shipment at all levels of volatility.

Finally, our model allows us to calculate the option value to firms of having fast transport available to them. We define this value as the percentage increase in profits for a firm that can react ex-post to demand shocks using air shipment less expected profits for a firm that must commit quantities to the market via ocean shipping before demand uncertainty is resolved. Employing our solutions for optimal air and ocean quantities and prices in each case, and using the demand parameters from Figure 
4, we can then calculate expected air shares and option values for different variance parameters and air freight premia. Table 2 shows that, for a given set of freight charges, the air share and the option value are sharply rising in the variance of demand. Both values are higher when the air freight premium is lower. Of course, these values are merely illustrative and depend on demand parameters. In Section 4 below we employ a simplified theoretical model and estimates from our empirical work to calculate the option value from the data and see how it has responded to technological and policy shocks that change air premia.

\section{Data, Specification and Estimation}

Our theory contains distinct predictions for both the likelihood that, and extent to which, firms use fast-arriving air cargo to hedge volatile and unpredictable changes in international demand. Greater volatility lowers the quantity of merchandise shipped by slow-moving ocean transport and raises the probability that air cargo will be employed. Conditional on air cargo being employed, greater volatility increases the share of air shipments in total quantities sold. Both the share of air cargo and the likelihood it is employed are decreasing in the air premium (the cost of air relative to ocean cargo), and increasing in the contemporaneous level of realized demand.

To investigate these hypotheses we employ data from the US "Imports of Merchandise" from 1990-2004. We have the value, weight in $\mathrm{kg}(W)$, freight and insurance charges $(F)$ by transport mode $(m=a(i r), o($ cean $))$ and the total number of shipments (Count) for US imports with detail by commodity groups $(i)$ at the 10-digit Harmonized System, and source country $(j)$, all at monthly frequencies within each year $(t) .{ }^{12}$ These data allows us to directly calculate whether air shipments were employed, their shares in total shipment quantities for each $i-j-t$ triplet, and the freight charge per $\mathrm{kg}$ for each mode.

In the model, the firm knows the distribution of demand it faces, and the volatility is a key variable in the decision process. Within each year $t$ we observe up to

\footnotetext{
${ }^{12}$ The 10 digit level of the HS has roughly 15000 categories. We only employ observations that enter the continental US. We exclude imports from Canada and Mexico as a large portion of imports from these countries is by road and we lack data on both the timing and the charges associated with these shipments.
} 
12 monthly prices ( $\mathrm{p}=$ value/weight) at which good $i$ from exporter $j$ was sold in the US market. We calculate the extent to which product prices move within each year $t$ using the coefficient of variation in year $t$ monthly prices for each $i-j-t$, $V(p)_{i j t}=\operatorname{stdev}\left(p_{i j t, \text { month }}\right) /$ mean $\left(p_{i j t, \text { month }}\right)$. In the empirics we capture volatility using the coefficient of variation and its lags. ${ }^{13}$ This is equivalent to assuming that firms use their (recent) experience of volatility in the US market to infer the volatility they will face and set their hedging strategy appropriately. Note that in the model volatility is synonymous with uncertainty, and so we take past volatility as our measure of uncertainty facing exporters. However, it may be that month to month volatility in demand is predictable due, for example, to seasonal shifts in demand. If exporters can perfectly forecast demand fluctuations, then there is no need to pay a premium for rapid shipments. In this case past volatilities should not predict the current period air share. In our base specifications we use all the variability in the raw price series to construct our volatility measures. In our robustness checks we experiment with a number of different volatility measures, including several meant to remove the predictable components of volatility.

The last variable suggested by the theory is the contemporaneous realization of demand, which we measure using the yearly product price in that period, $p_{i j t}$. Note that in our baseline specifications we follow the model in employing prices and their variance as the relevant measures of contemporaneous demand and demand volatility, rather than employing quantities and their variance. The logic of the model turns on how firms must fix ocean quantities well in advance of sales and only adjust quantities with air shipment at steeply higher cost should sufficiently great demand be realized (see Figure 3). This implies that a series of demand shocks below the threshold $\epsilon^{*}$ would result in no measured quantity volatility. In contrast, prices are responsive to the level and volatility of demand shocks along the entire continuum of shocks. This suggests prices are a better measure of the level and variance of demands. However, for robustness we also experiment with using quantity volatility with similar results.

\footnotetext{
${ }^{13}$ Using the history of volatility requires that an exporter-product be in the data continuously. Our most data intensive specification employs four lags of price volatility. This data restriction causes us to reduce our sample from 1113090 mixing observations in the US import data at HS10 annual observations to 201296 observations and tends to exclude lower valued trade flows.
} 
For completeness, we also include determinants of the shipping mix that vary across source countries and time but are outside the model. AvDays $s_{j}$ is the average ocean transit time between country $\mathrm{j}$ and the US. The real interest rate $\left(R_{j t}\right)$, captures inventory costs in the exporting country. The pipeline cost $\left(\right.$ pipe $_{j t}=\ln \left(R_{i j t}\right) * \ln \left(\right.$ AvDays $\left.\left._{j}\right)\right)$ captures the opportunity cost of locked up capital on lengthy ocean transit. An increase in the pipeline cost raises the cost of ocean transport relative to air shipment and raises the share of air shipments. As a final macro determinant we account for the exchange rate volatility $V\left(e_{j t}\right)$, constructed as the within year standard deviation of the monthly growth rate in the exchange rate between the US\$ and the exporter's currency. Note that exchange rate volatility that passes into import prices is already captured in $V(p)_{i j t}$, so this variable captures any volatility affects above and beyond prices.

In our model, the existence of mode-mixing occurs because a single firm optimizes over the ratio of air/ocean shipping, using more expensive air shipping when demand is more uncertain. Suppose instead that we are capturing in the data two types of firms, the first of which uses only ocean shipping and the second of which only uses air shipping. This might reflect subtle differences in product characteristics (despite measuring the goods at a very highly disaggregated HS 10 digit level), or differences in characteristics of the importing consumers. In the US data we do not observe firms directly, but we can address this concern in three ways. First, data for Danish exporters does report modal usage at the firm level. Taking a Danish firm selling an HS6 category to a single importer destination in a year as an observation, in 24 percent of the cases firms employ a mix of transportation modes. ${ }^{14}$ While this is a different dataset than what we employ, it does suggest mode-mixing is a relevant phenomenon for firms. Second, the US data report the number of distinct data records (export declaration forms) that comprise an aggregated exporter x production observation. Since different firms will fill out different export declaration forms, the number of distinct data records is presumably correlated with the number of distinct firms operating in that market. We include the number of records (Count) as a control in our regressions. Third,

\footnotetext{
${ }^{14}$ We thank Rasmus Jorgensen for providing us with this calculation based on Danish firm level exports from 1996-2006. Regretably the Danish data lack other variables such as freight charges necessary to estimate our complete model.
} 
we incorporate alternative measures of volatility below, including one calculated using only ocean-borne cargo prices. Were mode mixing to occur entirely across, rather than within, firms, we would not expect that changes in the history of demand volatility facing the ocean-using firm would have a strong effect on the contemporaneous level of shipments for the air-using firm.

Table 1 provides summary statistics on our included variables. Considering all US imports 1990-2004 from outside North America, 36 percent of (exporter-HS10 productyear) trade flows representing 71 percent of US trade by value enter the US through a mix of modes. Within this set, the average air share is 24 percent despite the fact that air freight rates per $\mathrm{kg}$ shipped are on average 5.7 times higher than ocean freight rates. Mixing occurs across a broad range of product types with a continuously varying share of air shipment. Figure 1 provides a histogram of air shares for the mixed mode observations with separate categories for five broad and dissimilar manufacturing types. All five categories are present in every bin in roughly similar proportion. The histogram excludes the observations that enter the US via only one mode (generally, ocean only). We examine below whether the ocean only observations can also be explained by our model, that is, if they correspond to products with demand volatility sufficiently low that the air shipment threshold is never reached.

Our measure of volatility $V(p)_{i j t}$ suggests that there is considerable movement in prices sold within the year for each exporter-product-year observation - much more than volatility associated with exchange rates. This also holds when we measure volatility using prices taken from only a single mode (ocean) or when measuring volatility in quantities. Some of this may represent measurement error in the price and quantity data, and so the key is whether variation in the volatility measures is correlated with the use of air shipments.

Toward this end, our data allow us to use variation across products, exporters and time to identify the hypothesized effects. Some HS product codes may be subject to more demand volatility than others (e.g. children's toys v. steel ball bearings) and different countries selling in the same HS product code (women's leather footwear) may be subject to varying degrees of volatility depending on whether they serve the high or low fashion segments of that market. Similarly, two firms facing the same 
absolute volatility may choose different hedging strategies depending on the (widely varying) air premium they must pay to access the US market. There are also large time series changes in the variables of interest. Over the 15 years spanned by our data there have been pronounced changes in the air premia - falling significantly from 1990-2001 and rising rapidly from 2001-2004 - in response to changes in technology, regulatory policy, and oil prices (Hummels 2007). The extent of volatility itself also changes over time for a given exporter-product, perhaps in response to changes in market structure, product characteristics, or the ability to manage inventories with improved information technology. In our data, $V(p)_{i j t}$ exhibits an aggregate downward trend of about 4 percent per year (conditioning on $i-j$ ), but with wide variation across the exporter-product observations in the signs and magnitudes of change over time. ${ }^{15}$

In our simplest specifications we exploit variation across all three dimensions of variation. In others we use exporter-product fixed effects and exploit only within $i-j$ variation over time in order to control for unobservables outside of the model that explain likelihood of air usage, and are correlated with model variables. For example, perishable goods may exhibit large fluctuations in price throughout the year and be air shipped because they "obsolesce" very rapidly. Fixed effects will then eliminate the over-time average perishability effect, identifying only off of within $i-j$ changes in air share, volatility, and other model variables. Similarly, any time-invariant country characteristic that is correlated with the use of air shipping and with model variables will be eliminated by the fixed effects. It is important to note that there exists substantial variation in both air shares and in volatility measures whether we exploit variation across all dimensions of the data or only exploit time series variation within an exporter-commodity pair. Considering all our data, the mean air share is 0.24 with a standard deviation of 0.28 . If we remove exporter-commodity means from the data and only exploit time series variation, the standard deviation is .14. That is, a time period that is one standard deviation about the $i-j$ mean has an air share about 60 percent larger.

\footnotetext{
${ }^{15}$ To see this, we examine year to year variation in our measure of volatility for each exporter-product observation. For a typical exporter-product, a one standard deviation increase in $V(p)_{i j t}$ is 50 percent higher than the exporter-product mean of $V(p)_{i j t}$.
} 


\subsection{The probability of mixing modes}

We begin by using a simple probit to model the probability that a trade flow uses a mix of transportation modes. Let the dependent variable $y=0$ if exporter $j$ shipping product $i$ uses only ocean shipment in time $t$, while $y=1$ if shipments from $i-j$ arrive by both ocean and air modes at time $t$. That is, we are estimating the likelihood of being in the shaded area of Figure 2. The independent variables are volatility (with lags), ocean shipping rates, and the additional controls noted above. Since we do not observe air freight rates for shipments where $q^{a}=0$, we exclude air charges as an explanatory variable. This regression examines the existence of mode-mixing but not its intensity, and exploits variation across $i-j-t$ dimensions of the data. ${ }^{16}$

Results are reported in Table 3. We find that the probability of mixing transport modes is positively correlated with higher demand volatility (contemporaneously and through the third lag) and higher contemporaneous realization of demand. The exchange rate volatility measure is also positively correlated with the use of hedging, but weakly. Firms are more likely to mix when pipeline costs are high (and it is expensive to leave goods in transit for weeks). The ocean freight charge has the wrong sign, but this is likely because we lack air freight as an additional control within countries. ${ }^{17}$

\subsection{The extent of hedging}

We next turn to regressions that examine the extent of hedging as these allow us to measure all theoretically indicated variables and also to exploit purely within $i-j$ variation in the data. Our base specification is

$$
\begin{aligned}
\ln \left(\frac{q_{i j t}^{a}}{q_{i j t}^{a}+q_{i j t}^{o}}\right)= & \theta_{t}+\delta_{0} \ln V(p)_{i j t}+\ldots+\delta_{4} \ln V(p)_{i j t-4} \\
& +\delta_{4} \ln \text { Air Charge } \text { Cht }_{i j}+\delta_{5} \ln \text { Ocean Charge } \text { Cijt }_{i j}+c_{i j}+u_{i j t}
\end{aligned}
$$

\footnotetext{
${ }^{16}$ It would be desirable to exploit within $i-j$ variation over time, but we cannot use mean differencing to eliminate fixed effects in the non-linear probit, and it is infeasible to directly estimate nearly 100,000 exporter-product combinations. We focus on within $i-j$ variation in the air share regressions below.

${ }^{17}$ In the mixed mode data we see a clear positive correlation in air and ocean rates across exporterproducts. Goods vary in their bulk and handling requirements and exporters vary in their distance to market and infrastructure quality. This means that some $i-j$ observations will exhibit higher air and ocean freight costs than others. Omitting the air freight (with a predicted negative coefficient) will negatively bias the ocean freight coefficient.
} 
We estimate equation (12) using simple OLS (and exploiting all $i-j-t$ dimensions of the data) and with a fixed effect $c_{i j}$, implemented via mean differencing. Columns 1 and 2 of Table 4 report the OLS and Fixed Effect results of the baseline specification. The fixed effects control for any exporter-product characteristic that could affect the extent of hedging and be correlated with volatility or other model variables. Columns 3 and 4 augment the OLS and Fixed Effect specifications with additional controls (contemporaneous demand, interest rate, pipeline cost, and number of distinct records) as explained above. ${ }^{18}$

Examining Table 4, we see that volatility (up to the 4th lag) affects the extent of hedging. Recall the channel through which this operates. A history of demand volatility causes the firm to lower ocean quantities in the first period in order to avoid having excessive quantities in the second period. For similar demand realizations, more volatility then leads to a larger share of demand being served by air shipping. We also see that a high contemporaneous realization of demand calls forth a larger share of air shipping in total quantities. Now that we have both air and ocean freight rates in the equation we see that signs are as predicted by the model, with hedging used less extensively when the relative cost of hedging is high (that is, when air shipping is expensive and ocean shipping is cheap).

Notably, the volatility coefficients are smaller when using fixed effects. This could be because unobservable $i-j$ characteristics are spuriously correlated with volatility and air shipment. Or it could be that by restricting ourselves to only within variation (identifying off of changes in volatility for Chinese ball bearings) we are throwing out useful variation in volatility across the $i-j$ 's (comparing volatility in Chinese ball bearings to volatility in Italian men's suits). In any case, we follow a conservative estimation strategy and restrict our attention to within $i-j$ variation henceforth.

\subsection{Robustness Exercises}

In this section we examine whether our main findings are robust to different measures of volatility, different treatment of the time series properties of the data, and to the possibility that volatility is endogenous to the hedging response we seek to identify.

\footnotetext{
${ }^{18} \mathrm{AvDays}_{j}$ is excluded since it is collinear with our fixed effects.
} 


\subsubsection{Stability of the Estimates over Time}

Our data sample spans 1990-2004, and from roughly 2001 onwards there has been a marked fall in the use of air shipping on world markets. This raises the question of what has caused the reductions in air shipping and whether this has changed the fundamental relationship between uncertainty and air shipping that we investigate. Recall that in our base specifications we employ year dummies, so time series changes in the use of air shipping will be absorbed into these intercepts. We also experiment with interacting our volatility measures with a post 2001 dummy variable. The relationship between volatility and air shipping is consistent across the two time periods. ${ }^{19}$

\subsubsection{Other Measures of Demand Volatility}

An examination of Figure 3 suggests two alternative measurements of volatility. Below $\epsilon^{*}, \mathrm{Q}$ does not change in response to demand shocks. Above $\epsilon^{*}, Q$ changes while the response of price to changes in $\epsilon$ is damped by the ability to bring additional (air) quantities onto the market. Accordingly, we employ the volatility of total quantities sold $V(Q)_{i j t}$, and its lags, constructed in a manner analogous to $V(p)_{i j t}$. For similar reasons we also construct a price volatility measure using only prices for ocean shipped goods, $V(p o)_{i j t}$. As we note above, this measure has the added benefit of helping us to identify whether our single firm model is a sensible way to view the data, in contrast to a model in which mixing happens because of two distinct firm types, one of which uses ocean and one of which uses air shipping. In this two-types model, we would not expect that changes in the history of demand volatility facing the ocean-using firm would have a strong effect on the contemporaneous level of shipments for the air-using firm.

As we noted above, in our model volatility and uncertainty are synonymous, yet it may be that some shocks to demand and resulting changes in price are predictable by the firm. For example, prices may change seasonally and prices at time $t$ may be closely related to prices at time $t-1$. If so, predictable changes in demand can

\footnotetext{
${ }^{19}$ What caused the fall in air shipping? BLS price indices show sharp rises in the cost of air freight after 2001 which in our model will reduce the use of the air option. In addition, it is notable that most of the reduction can be attributed to cross-commodity rather than within commodity changes. That is, there is very little change in the use of air shipping within a given exporter-product pair, but large reductions in imports for those goods such as electronics that intensively use air shipping.
} 
easily be anticipated and served by low cost ocean shipping. Since we are interested in the unpredictable component of changes in demand, we experiment with two measures meant to purge the predictable variation in prices from our volatility measures. In the first, we regress prices for ijt on month dummies (allowing different coefficients for each $i j$ time series), collect the residuals from that regression, and reconstruct our price volatility measures using the residuals. In the second, we follow the same procedure but include the first observable lag of prices along with the month dummies in the initial regression. ${ }^{20}$

In Table 5 we report results of the base specification using these four new measures of volatility. The results are very similar in both sign and magnitudes to the Table 4 results regardless of which volatility measure we use. Higher volatility in quantities, in ocean-only prices, or in prices purged of their predictable component leads firms to employ air shipments more intensively. Notably, price volatility constructed using only ocean shipments shows a similar effect on the air share as using prices from combined modes. This provides indirect evidence against the idea that air / ocean mixing reflects two distinct types of firms operating in the market. Why doesn't purging predictable price movements from the volatility measure affect our estimates? Simply put, monthly dummies and the first lag of prices explains relatively little of the variation in prices so that volatility measures with and without this information are correlated 0.98 . This suggests that month-on-month price variation is hard to predict for the econometrician - and given the close match of our model to the data - hard to predict for firms as well.

\subsubsection{Serial Correlation}

Next, we consider the possibility that there is serial correlation across time within each $i-j$. To address this we re-estimate the model in first differences and capture the industry's history of demand smoothing with the lag of the dependent variable. A high air share in the past reveals that the firm was subject to demand volatility. Since

\footnotetext{
${ }^{20}$ We have also experimented with imposing different structures of seasonality, and pooling the fitting regression at different levels of aggregation or across all exporters shipping the same commodity with no change in results.
} 
firms that were subject to demand volatility in the past shift into a faster transport mix, this results in a positive relationship between the current air share and its lags. In addition, past demand volatilities are a function of the firm's effort to smooth demand in the past. To account for these channels, we estimate the partial effect of the past demand volatility on the current air share, holding fixed the industry's history of the transportation mix.

We augment (12) with the first lag of the dependent variable, drop the 4th lag of the demand volatility and first difference to obtain

$$
\begin{aligned}
\Delta \ln \left(S_{i j t}\right) & =\Delta \ln \left(S_{i j t-1}\right)+\Delta \theta_{t}+\Delta \delta_{0} \ln \left(V(p)_{i j t}\right)+\ldots+\Delta \delta_{3} \ln \left(V(p)_{i j t-3}\right)+ \\
& +\Delta \delta_{5} \ln \left(\text { Air Charge }_{i j t}\right)+\Delta \delta_{6} \ln \left(\text { Ocean Charge }_{i j t}\right)+\Delta X+\Delta v_{i j t} .
\end{aligned}
$$

$\Delta$ is the first difference operator, $\Delta X$ denotes our control variables in first differences, and the exporter-commodity fixed effect is eliminated by first differencing.

From equation (12) we see that the air share in $t-1$ is a function of the error in $t-1$, which means that the difference in the error term $\left(v_{i j t}-v_{i j t-1}\right)$ will be correlated with the lag of the first difference of the air share $\left(S_{i j t-1}-S_{i j t-2}\right)$. Accordingly, we instrument for the first lag of the difference in the air share, $\Delta \ln \left(S_{i j t-1}\right)$, using higher order lags of the first difference of the air share. ${ }^{21}$

Table 6 shows the results from the FD-2SLS estimation. In the first column we include the first lag of the dependent variable, instrumenting with the second lag. In the second column we include first and second lags, instrumenting with the third lag. Either way we find that the magnitudes and signs of the coefficients are similar to the fixed effect estimation: an increase in the past demand volatility results in a higher air share in the current period.

\subsubsection{Feedback Effects of Hedging to Observed Prices}

The final robustness exercise examines the endogeneity of the price volatility with respect to an exporter's hedging strategy. Figure 3 shows that a hedging strategy dampens the effect of demand shocks on market prices for high realizations of $\epsilon$, lowering

\footnotetext{
${ }^{21}$ That is, we assume that the error term in a given period $t$ can be correlated with the endogenous regressors in the current or future periods but not with their past.
} 
observed price volatility. In our specification this implies a downward bias on the coefficients of price volatility, because whenever the air share is high, exporters smooth high price shocks.

To examine the impact of the feedback effect from the air shares to the prices and price volatility, we instrument for past price volatility. Table 7 reports results from FD2SLS using similar specifications as in Table 6. For comparison, column (1) of Table 7 instruments for the lag of the air share and the contemporaneous price. Column (2) instruments for the current period price volatility in addition to the variables in column (1). ${ }^{22}$ As we expect from the theory, all coefficients on the price volatilities increase. The specification in column (3) adds the lag of the first difference of the price volatility to the list of instrumented variables. ${ }^{23}$ This variable is endogenous by construction due to first differencing. Again the coefficients on the history of the price volatilities increase, but precise identification in this case is difficult as we now instrument for four variables employing only their higher order lags of levels and differences as instruments. Column (4) drops the current period price volatility which is insignificant in column (3) to re-establish significant estimates on the lagged price volatilities. Table (6) says that as we account for potential feedback effects from a hedging strategy to the price volatilities, the impact of the price volatilities increases. This is consistent with our theory, where exporters subject to high price shocks smooth the price realizations with additional air shipments.

\section{The Option Value of Air Transport}

Air transport allows firms to decrease their first period shipment and take advantage of favorable market conditions after demand uncertainty is revealed. In other words, air transport is a real option that a firm can realize at the price of higher transportation costs. In this section, we employ a simplified model with discrete rather than continuous realizations of demand. This allows us to provide analytical expressions for many, but not all, of the model predictions described in Section 2. In addition, it allows us to use estimates from our empirical section to provide back-of-the-envelope calculations

\footnotetext{
${ }^{22}$ The column (1) instruments are $\Delta S_{i j t-1}, \Delta S_{i j t-3}, \Delta p_{i j t-2}$. The column (2) instruments are $\Delta S_{i j t-1}, \Delta S_{i j t-3}, \Delta p_{i j t-2}, \Delta V(p)_{i j t-4}, \Delta V(p)_{i j t-2}$.

${ }^{23}$ The column (3) and column (4) instruments are $\Delta S_{i j t-2}, \Delta S_{i j t-3}, \Delta p_{i j t-2}, \Delta V(p)_{i j t-4}, V(p)_{i j t-2}$.
} 
of the value to firms of having fast transport available.

The model set up is the same as in Section 2, except that we assume a linear demand function $P(Q)=(a+\epsilon-b Q)$, where the random variable $\epsilon$ captures the demand uncertainty, and $\epsilon=\gamma$ or $\epsilon=-\gamma$ with equal probability. Here, demand uncertainty enters as a $E(\epsilon)=0$ parallel shift of the demand curve as opposed to the Section 2 assumption of uncertainty rotating the demand curve. ${ }^{24}$

Following the derivation in Section 2, we solve the problem backwards. In the second period the firm takes the ocean quantity and the realization of the shock $\epsilon$ as given and maximizes

$$
E \pi_{2}^{\operatorname{mix}}\left(q^{a}\right)=\left(a+\epsilon-b\left(q^{o}+q^{a}\right)\right)\left(q^{o}+q^{a}\right)-q^{o} f^{o}-q^{a} f^{a}
$$

with respect to the air shipment. This results in the optimal air quantity $q^{a}(\epsilon)=$ $\frac{a+\epsilon-f^{a}}{2 b}-q^{o}$. As in Section 2, we write first period expected profits by substituting the optimal air shipment into the profit function and taking expectations to obtain

$$
\begin{aligned}
E \pi_{1}^{\operatorname{mix}}\left(q^{o}\right) & =\frac{1}{2}\left\{\left[a-\gamma-b\left(q^{o}\right)\right] q^{o}-q^{o} f^{o}\right\} \\
& +\frac{1}{2}\left\{\left[a+\gamma-b\left(q^{o}+q^{a}(\gamma)\right)\right]\left(q^{o}+q^{a}(\gamma)\right)-q^{o} f^{o}-q^{a}(\gamma) f^{a}\right\}
\end{aligned}
$$

Solving for optimal ocean quantities yields

$$
q^{o^{*}}=\frac{1}{2 b}\left(f^{a}+a-\gamma-2 f^{o}\right)
$$

Ocean quantities are increasing in the air freight premium and decreasing in the variance of demand, as firms subject to potentially very low realizations of demand will hold back quantities until after uncertainty is resolved. Substituting $q^{0^{*}}$ into the expression for optimal air shipment, we arrive at

\footnotetext{
${ }^{24}$ Given this specification of additive demand shocks, it is possible that a sufficiently low demand realization would induce the firm to throw away quantities shipped in the firm period because the marginal revenue from their sale would be negative. This implies a richer model of inventory holding than we can take to the data because while we observe modal choice we cannot observe firms' disposal behavior. To keep this section simple, we rule out disposal by assumption, and thank our referee for pointing out this problem.
} 


$$
q^{a^{*}}=\frac{1}{b}\left(\gamma+f^{o}-f^{a}\right)
$$

Note that $q^{a}(\gamma)>0 \Leftrightarrow \epsilon>f^{a}-f^{o}$. Since $\epsilon$ takes on discrete values of $(-\gamma, \gamma)$ the problem simplifies considerably relative to our Section 2 model, and the range of demand realizations determines three possible cases. In the first case, $\gamma<f^{a}-f^{o}$, the highest realization of demand yields an increase in prices that is less than the air freight premium. As a result, air shipment is never optimal and only ocean shipments are employed. (This result is similar to the case where $z<z^{*}$ in Figure 2 from the continuous model.) Here, the monopolist sets ocean quantities by maximizing profits subject to the expected value of demand, or $E(P(Q))=(a-b Q)$.

When demand is more variable, $\gamma>f^{a}-f^{o}$, ex-post realizations of demand determine modal choice discretely. For low realizations of the shock, $\epsilon=-\gamma<f^{a}-f^{o}$, and only ocean shipment is chosen. For high realizations of the shock, $\epsilon=\gamma>f^{a}-f^{o}$ and additional air quantities are brought into the market. This is the primary difference between this simplified model and the continuous demand distribution from Section 2 . In the simple model the probability of choosing air shipping depends only on whether demand is variable enough and whether the high demand state is realized. It is therefore independent of the ocean quantities chosen in the first stage.

We can now apply optimal air and ocean quantities to calculate the expected share of air shipments given freight rates and demand volatility, as

$$
S^{a}=-\frac{f^{a}-f^{o}-\gamma}{\gamma+a-f^{a}}
$$

As in the model of Section 2, the average air share is increasing in the variance of demand, $\frac{\partial S^{a}}{\partial \gamma}=\frac{a-f^{o}}{\left(\gamma+a-f^{a}\right)^{2}}>0$.

Finally, the simplified model allows us to calculate the option value to firms of having fast transport available to them. We define this value $\Omega$ as expected profits for a firm that can react ex-post to demand shocks using air shipment less expected profits for a firm that must commit quantities to the market via ocean shipping before demand uncertainty is resolved. Employing our solutions for optimal air and ocean quantities and prices in each case, we find 


$$
\Omega \equiv \frac{1}{4 b}\left(\gamma-\left(f^{a}-f^{o}\right)\right)^{2}
$$

The option value is a function of the price premium commanded in high demand periods relative to the air premium that must be paid to take advantage of these high demand periods. For a sufficiently high variance of demand such that air shipment might be employed, $\gamma>f^{a}-f^{o}$, the option value of air shipments is decreasing in the air premium, and increasing in the variance of demand, since

$$
\frac{\partial \Omega}{\partial \gamma}=-\frac{\partial \Omega}{\partial\left(f^{a}-f^{o}\right)}=\frac{1}{2 b}\left(\gamma+f^{o}-f^{a}\right) .
$$

It would be desirable to calculate $\Omega$ directly, but this requires information we lack regarding the demand parameter $b$, and the calculation is sensitive to the units employed in the volatility measure. We can arrive at a more manageable expression by expressing the expected air share as a function of $\gamma$, and substituting this into the expression to obtain

$$
\Omega\left(S^{a}\right)=\frac{\left(S^{a}\right)^{2}}{\left(S^{a}-1\right)^{2}} \frac{\left(a-f^{o}\right)^{2}}{4 b} .
$$

We can use this expression to describe marginal changes in model variables (demand volatility, the air freight rate) acting through changes in the share of air shipping. For example, to analyze a change in volatility we write, $\frac{\partial \ln \Omega}{\partial \ln \gamma}=\frac{\partial \ln \Omega}{\partial \ln S} \frac{\partial \ln S}{\partial \ln \gamma}$. The elasticity of the option value with respect to the air share is

$$
\frac{\partial \ln \Omega}{\partial \ln S}=-\frac{2}{s-1}
$$

In our sample, the average air share for products that mix modes is 0.24 , so $\frac{\partial \ln \Omega}{\partial \ln S}=$ 2.63. Our Table 4 estimates show a 0.07 percent increase in the average air share for a one percent increase in the first lag of the price volatility. Combining these yields $\frac{\partial \ln \Omega}{\partial \ln \gamma}=\frac{\partial \ln \Omega}{\partial \ln S} \frac{\partial \ln S}{\partial \ln \gamma}=.184$ percent. That is, a one percent increase in the first lag of the price volatility raises the option value of air transport by about $1 / 5$ of a percent. We also estimate that volatility measured at one, two and three lags has an independent positive effect on the air share. Suppose a product were to experience a 1 percent increase in volatility at each of the three lags. The cumulative effect on the option 
value would then be $\frac{\partial \ln \Omega}{\partial \ln \gamma}=.33$ percent.

We can also use this calculation to infer differences in option values across goods depending on the volatility of demand they face. Recalling Table 1, the mean of (normalized) price volatility is about 0.52 with a standard deviation of 0.49 . This means that a product with volatility one standard deviation above the mean is about 94.2 percent more volatile, which increases the expected air share by about 6.6 percent. This implies an increase in the option value of air transport by about 17.1 percent.

The option value depends on air transport costs and these are sensitive to changes in policies. Micco and Serebrisky (2006) estimate that Open Skies Agreements (treaties that permit competition in international aviation markets) reduce air transport costs by 9 percent. According to our Table 4 estimates, a 9 percent reduction in air transport costs raises the air share by about 6.5 percent. Evaluated at the average air share of 0.24 , signing open skies agreements raises the option value of air shipping by $\frac{\partial \ln \Omega}{\partial \ln f^{a}}=$ $\frac{\partial \ln \Omega}{\partial \ln S} \frac{\partial \ln S}{\partial \ln f^{a}} \frac{\partial \ln f^{a}}{\partial O S A}=17.02$ percent

Hummels (2007) reports that the cost of air transport fell 80 percent from 1965 to 2000 largely as a result of innovation in jet aircraft. This caused the air share of US imports from outside of North America to rise from 8 to 36 percent, and the air share in US exports to outside North America to rise from 11.9 to 57.6 percent. To evaluate these non-marginal changes in freight prices and air shares, we can express the ratio of the option value at two points in time. Substituting these air shares into equation (21) above, and assuming no other change in parameters, ${ }^{25}$ we arrive at

$$
\begin{aligned}
\Omega(\text { US imports, } 2000) / \Omega(\text { US imports, } 1965) & =31.3 \\
\Omega(\text { US exports, } 2000) / \Omega(\text { US exports, } 1965) & =101.1
\end{aligned}
$$

To use the model's interpretation, the enormous drop in air shipping costs in this period made feasible a broad use of air transport as an option to smooth demand uncertainty. The value of this option rose 31-fold for US imports and 100-fold for US

\footnotetext{
${ }^{25}$ Hummels (2007) also shows that ocean shipping costs were largely unchanged over this period, so we take $f^{o}$ as fixed.
} 
exports over a 35 year span.

\section{Conclusion}

Physically moving goods between distant locations introduces a significant lag between when a product is shipped and when it arrives. This can be especially problematic for firms facing volatile demand, who must then place orders before knowing the resolution of demand uncertainty. One solution for these firms is to bring producers and consumers closer together in space. We explore an alternative solution: using airplanes to bring producers and consumers closer in time.

In our model of this process, fast transport allows firms to lower the quantities shipped prior to the resolution of demand, thereby reducing the risk of having large quantities on hand during a low demand period. It also allows firms to respond quickly to favorable demand realizations, bringing greater quantities into the market in these periods. Fast transport thus provides firms with a real option to smooth demand volatility.

The model predicts that the likelihood and extent to which firms employ air shipments is increasing in the volatility of demand they face, decreasing in the air premium they must pay, and increasing in the contemporaneous realization of demand.

We test and find support for all three conjectures using detailed US imports data from 1990-2004. Air shipment is sensitive to past volatility out to the third lag, and the cumulative impact of the demand volatility on air shipments is similar in magnitude to the impact of the ocean freight rate. These estimates are robust to respecification, accounting for the firm's past history of the transport mix, and controlling for other plausible determinants of the transport mix.

We use a simplified model to express the option value associated with fast transport as a function of demand volatility and shipping costs, which in turn depend on variation in goods characteristics, technology, and policy variables. A one standard deviation increase in the past demand volatility raises the option value of air transport by about 17.1 percent. Liberalization of air cargo services raises the option value by 17.02 percent. The rapid decline in air transport costs associated with the introduction of jet engines increased the option value 31-fold for US imports and 100-fold for US 
exports.

These results provide insights into several broader problems. One, we provide evidence for a specific micro channel - hedging demand shocks - that helps explain why firms are willing to pay a very large premium to air ship products. Two, as shown in Aizenman (2004), exchange rate pass through is increasing in the share of last minute shipments. To the extent that air shipping as a real option varies across exporters and products (due to variation in both demand volatility and the air premium) this may help explain where exchange rate pass through is large or small. Three, express air cargo carriers such as Fed Ex are active both in domestic and international markets. Our results provide evidence for a specific but widely employed adjustment cost - paying a premium for rapid transport - facing firms subject to demand shocks. 


\section{References}

Aizenman, J., May 2004. Endogenous pricing to market and financing cost. Journal of Monetary Economics 51 (4), 691-712.

Baumol, W. J., Vinod, H. D., 1970. An inventory theoretic model of freight transport demand. Management Science 16 (7), 413-421.

Evans, C., Harrigan, J., 2005. Distance, time and specialization: Lean retailing in general equilibrium. American Economic Review 95 (1), 292-313.

Fisher, M., Raman, A., 1996. Reducing the cost of demand uncertainty through accurate response to early sales. Operations Research 44 (1), 87-99.

Gordon, R., 1990. The measurement of durable goods prices. University of Chicago Press.

Harrigan, J., Venables, A., March 2006. Timeliness and agglomeration. Journal of Urban Economics 59, 300-316.

Hummels, D., 2007. Transportation costs and international trade in the second era of globalization. Journal of Economic Perspectives 21 (2).

Hummels, D. L., Schaur, G., 2009. Time as a trade barrier. Working Paper.

Micco, A., Serebrisky, T., 2006. Competition regimes and air transport costs: The effects of open skies agreements. Journal of International Economics 70 (1), $25-51$. 

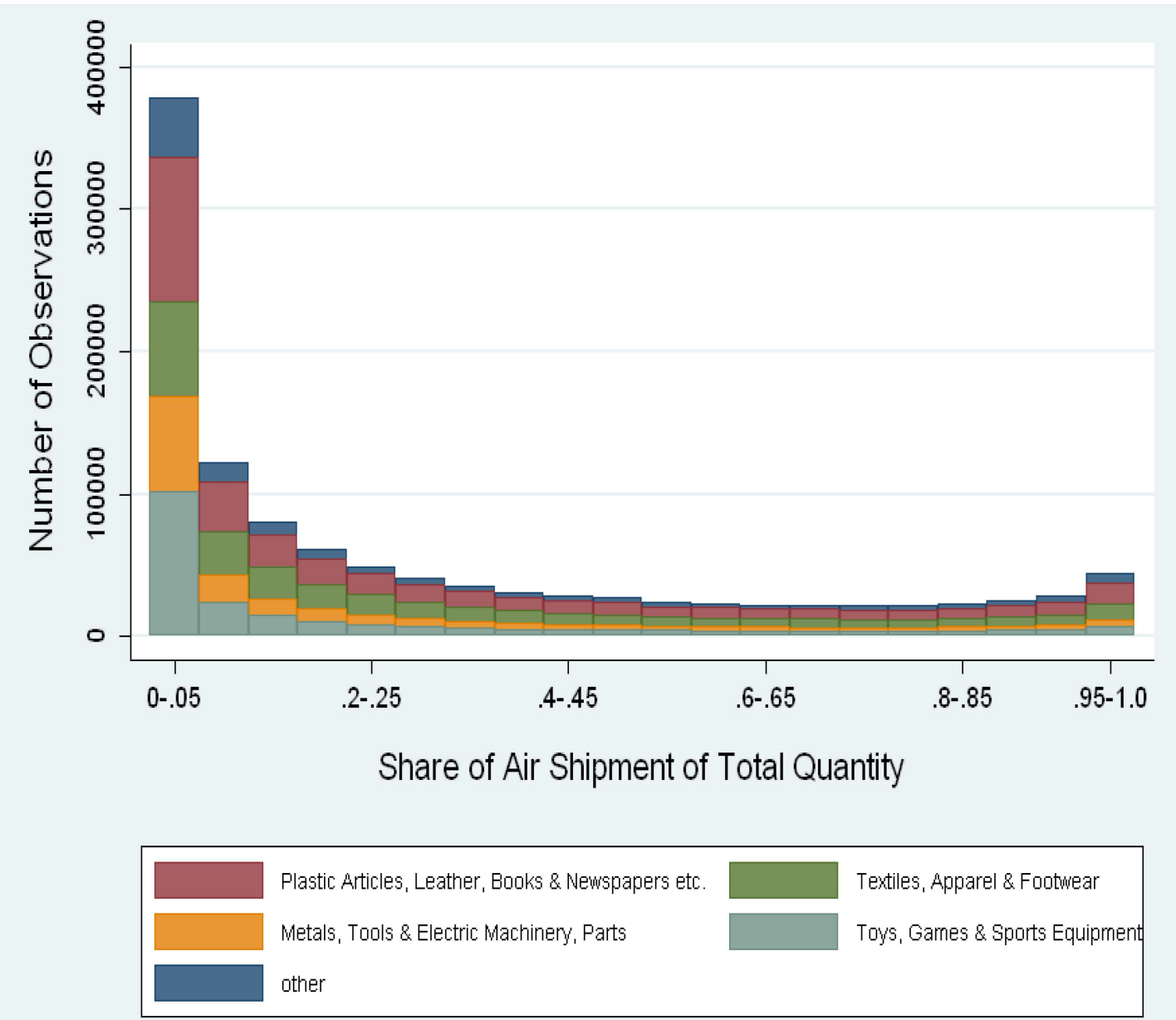

Note: An observation is a unique exporter-HS10 product flow in each year from 19902004. North American trade and observations with zero air shipments or zero ocean shipments are excluded (68 percent of total).

Figure 1: Air Cargo Shares in US Imports 


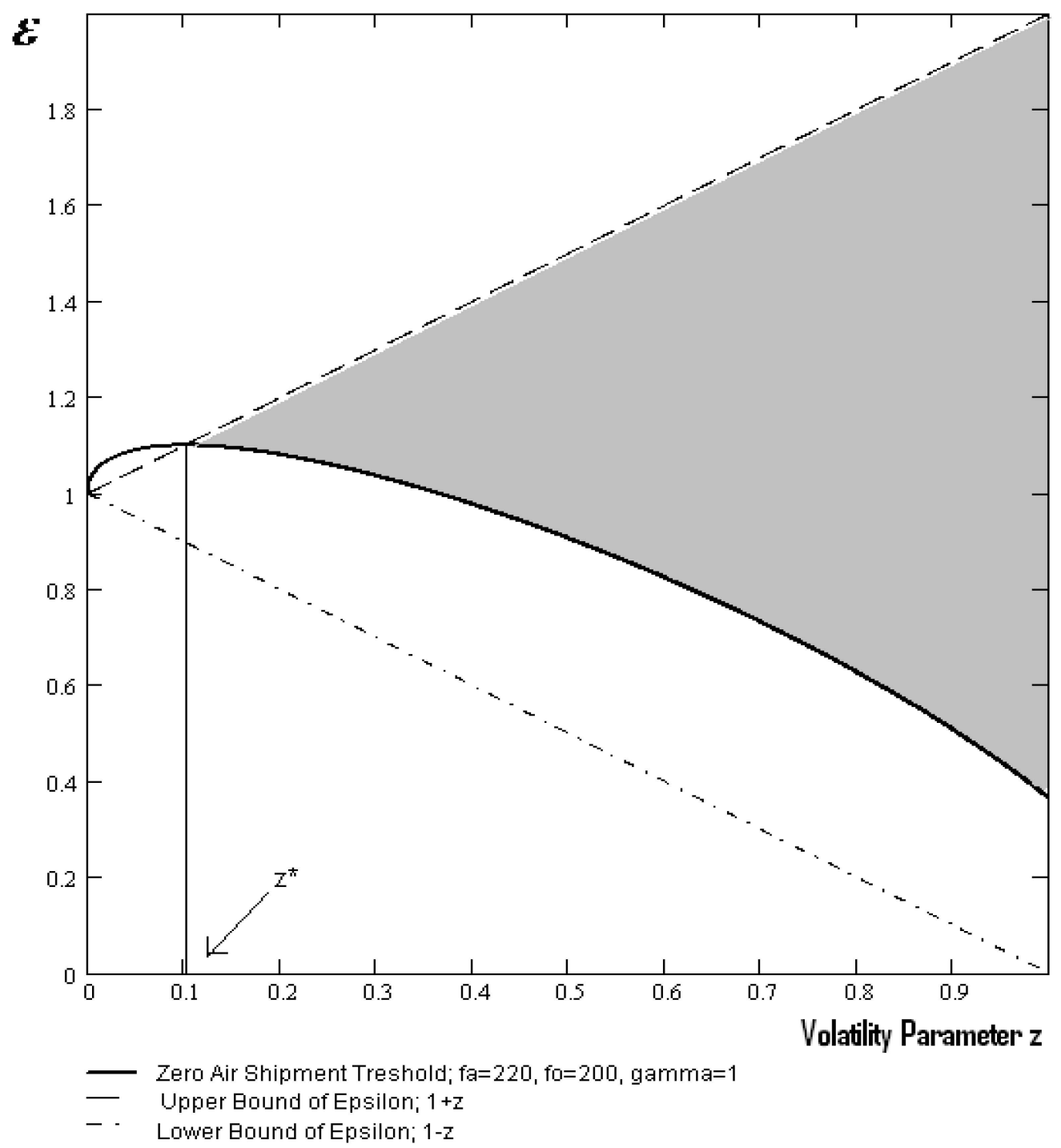

Note: Dotted lines form upper and lower bound of demand realization. Solid line is zero air shipment threshold, air shipment occurs in gray area. The parameters are $a=1000, b=1$.

Figure 2: The Air Shipment Threshold 


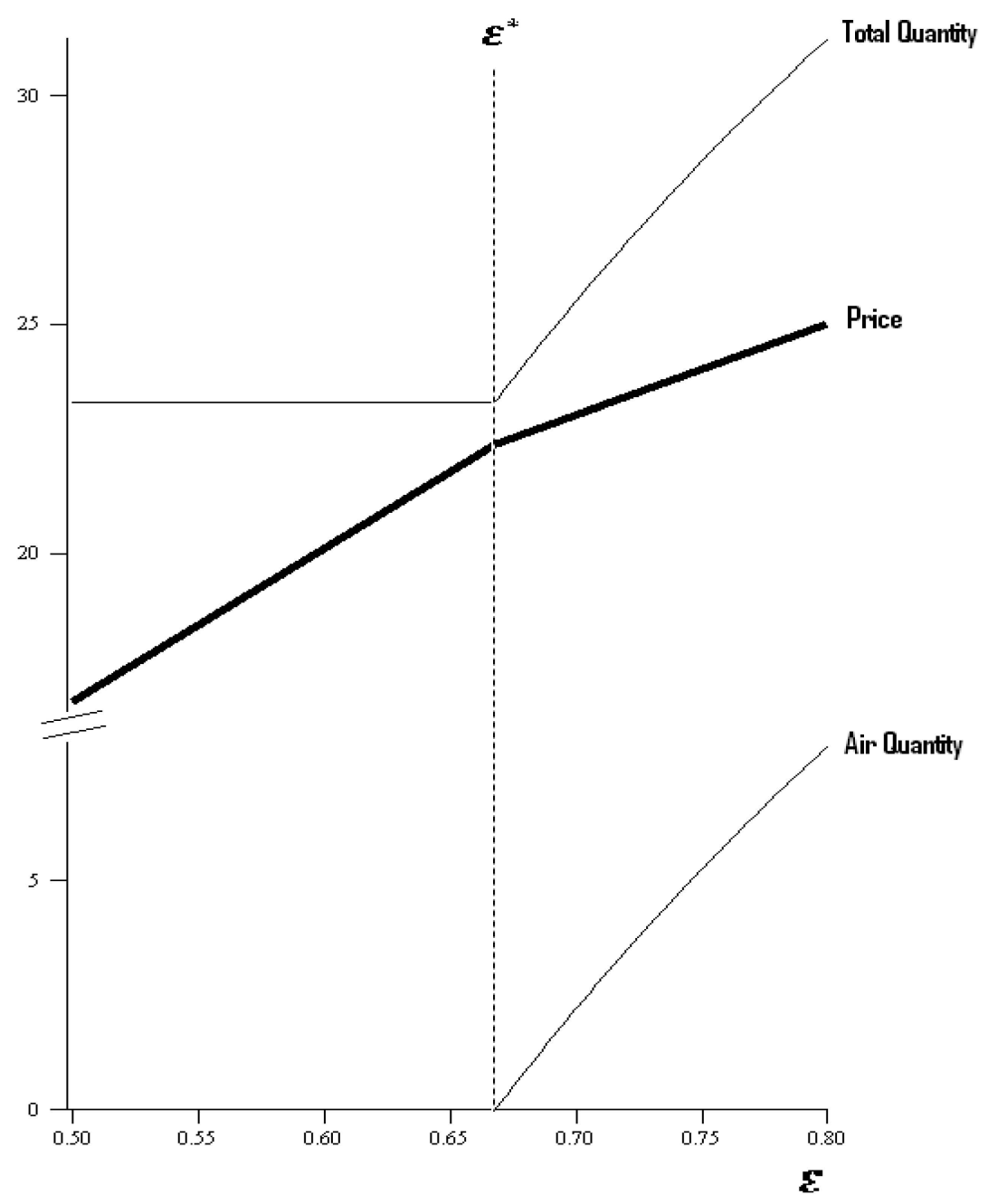

Figure 3: Prices and Quantities at Different Realizations of the Shock 


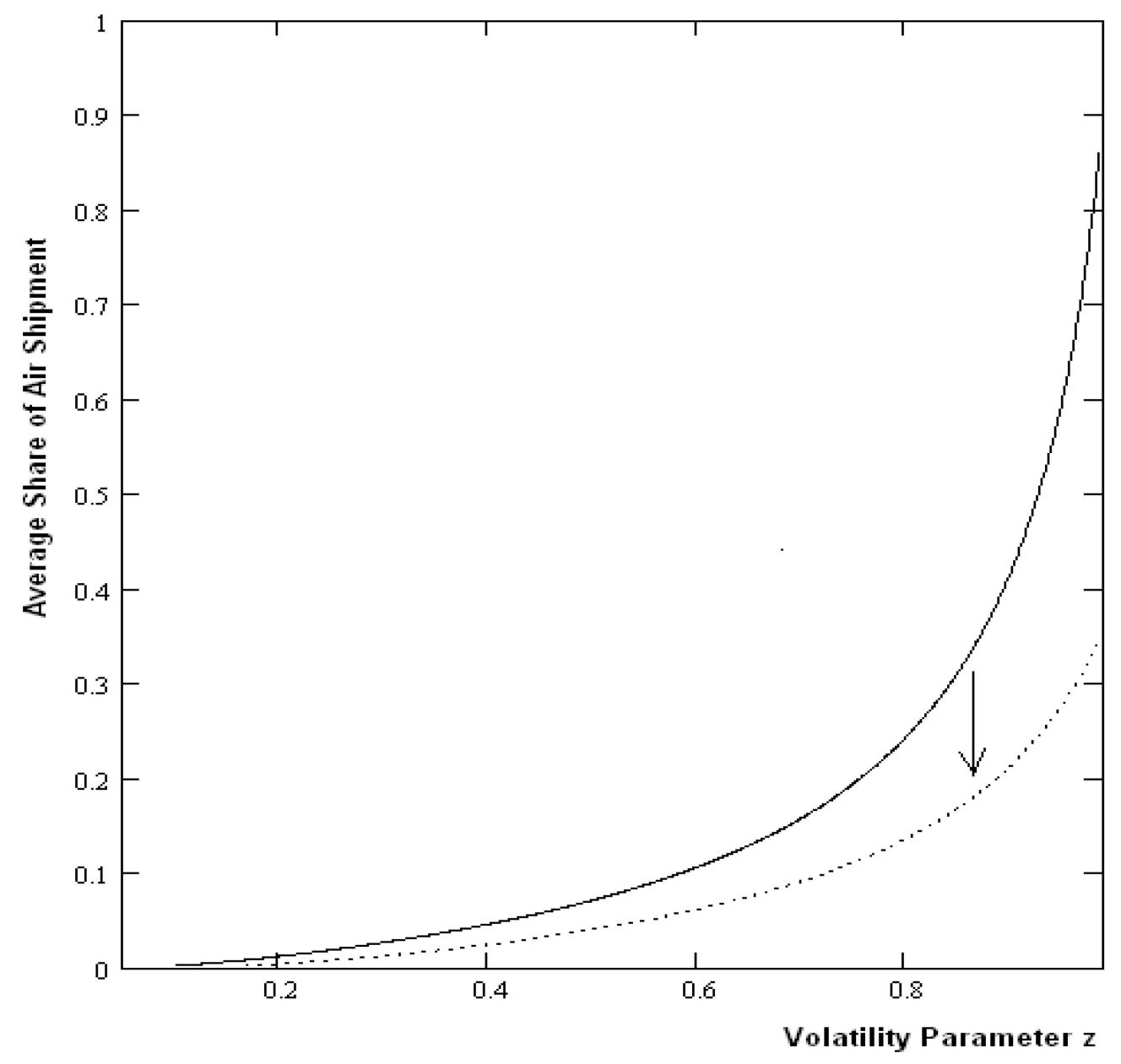

Awerage Air Share at $f a=210$ and fo $=200$

Average Air Share at $f a=220$ and fo $=200$

Figure 4: The Share of Air Shipments in Total Quantity 
Table 1: Variable Description

\begin{tabular}{|c|c|c|c|c|}
\hline Variable & "Description & Mean & St. Dev. & Source \\
\hline$S_{i j t}$ & Air Share in Total Quantity & 0.24 & 0.28 & \\
\hline Air Charge Cijt & Air freight rate in US\$ per $\mathrm{kg}$ & 3.38 & 22.12 & US \\
\hline Ocean Charge $_{i j t}$ & Ocean freight rate in US\$ per $\mathrm{kg}$ & 0.59 & 0.69 & Census \\
\hline $\mathrm{V}(\mathrm{p})_{i j t}$ & $\begin{array}{l}\text { Price volatility; coefficient of variation in } \\
\text { within-year prices }\end{array}$ & 0.52 & 0.49 & Imports \\
\hline $\mathrm{V}(\mathrm{psa})_{i j t}$ & $\begin{array}{l}\text { Same as } V(p) \text { after adjusting for monthly } \\
\text { seasonality }\end{array}$ & 0.49 & 0.4 & of \\
\hline $\mathrm{V}(\mathrm{psa} \& \mathrm{~L})_{i j t}$ & $\begin{array}{l}\text { Same as } V(p) \text { after adjusting for monthly } \\
\text { seasonality and the past price }\end{array}$ & 0.49 & 0.4 & 01 \\
\hline $\mathrm{V}(\mathrm{po})_{i j t}$ & $\begin{array}{l}\text { Ocean price volatility; calculated as } V(P) \text {, } \\
\text { using only ocean shipments }\end{array}$ & 0.45 & 0.39 & Merchandise \\
\hline $\mathrm{V}(\mathrm{Q})_{i j t}$ & $\begin{array}{l}\text { Weight volatility; coefficient of variation in } \\
\text { within year quantities (weight) }\end{array}$ & 0.84 & 0.48 & Data \\
\hline $\mathrm{P}_{i j t}$ & Unit value in US\$ per $\mathrm{kg}$ & 38.69 & 703.23 & \\
\hline Count $_{i j t}$ & Total shipments per year & 371.91 & 1402.82 & \\
\hline $\mathrm{R}_{j t}$ & Real interest rate & 6.29 & 6.96 & World Dev. Indicators \\
\hline AvDays $_{j}$ & $\begin{array}{l}\text { Average number of days of vessel transport } \\
\text { from each exporter to the US }\end{array}$ & 22.09 & 5.36 & www.shipguide.com \\
\hline $\mathrm{V}(\mathrm{e})_{j t}$ & $\begin{array}{l}\text { Standard deviation of the monthly growth } \\
\text { rate of the US\$ exchange rate within years }\end{array}$ & 0.02 & 0.02 & IFS Data \\
\hline Pipeline Cost $_{j t}$ & Interaction of $\log$ of $r_{j t}$ and $\log$ of $a v d a y_{j}$ & & & \\
\hline
\end{tabular}


Table 2: Expected Air Share and Option Value of Air Transport

\begin{tabular}{|c|c|c|c|c|}
\hline \multirow{3}{*}{$\begin{array}{c}\text { Variance } \\
\text { Parameter z }\end{array}$} & \multicolumn{2}{|c|}{ Expected Air Share } & \multicolumn{2}{|c|}{ Option Value } \\
\hline & Higher & Lower & Higher & Lower \\
\hline & Air Premium & Air Premium & Air Premium & Air Premium \\
\hline 0.1 & 0 & 0.002 & 0.000 & 0.002 \\
\hline 0.2 & 0.004 & 0.012 & 0.005 & 0.024 \\
\hline 0.3 & 0.012 & 0.027 & 0.035 & 0.082 \\
\hline 0.4 & 0.024 & 0.046 & 0.095 & 0.182 \\
\hline 0.5 & 0.040 & 0.071 & 0.193 & 0.332 \\
\hline 0.6 & 0.062 & 0.106 & 0.340 & 0.55 \\
\hline 0.7 & 0.091 & 0.158 & 0.552 & 0.861 \\
\hline 0.8 & 0.136 & 0.243 & 0.857 & 1.321 \\
\hline 0.9 & 0.213 & 0.416 & 1.315 & 2.063 \\
\hline
\end{tabular}

The option value is the percentage increase of expected profits with the air shipment option compared to expected profits without the air shipment option. We simulate a 9 percent decrease in the air freight rate. Base Values: Unit air freight rate $=220$, unit ocean freight rate $=200$, demand intercept $=1000$, demand slope $=1$. Lower Air Premium: The air freight rate changes to 210 . 
Table 3: Probability of Mixing

\begin{tabular}{|c|c|c|c|}
\hline & $\begin{array}{c}\text { Probit } \\
(1)\end{array}$ & $\begin{array}{c}\text { Probit } \\
(2)\end{array}$ & $\begin{array}{c}\text { Probit } \\
(3)\end{array}$ \\
\hline Price volatility: $\mathrm{V}(\mathrm{p})_{i j t}$ & $\begin{array}{c}.408 \\
(.003)^{* * * *}\end{array}$ & $\begin{array}{c}.389 \\
(.004)^{* * *}\end{array}$ & $\begin{array}{c}.378 \\
(.005)^{* * *}\end{array}$ \\
\hline 1st Lag & $\begin{array}{c}.136 \\
(.003)^{* * *}\end{array}$ & $\begin{array}{c}.111 \\
(.003)^{* * *}\end{array}$ & $\begin{array}{c}.099 \\
(.004)^{* * *}\end{array}$ \\
\hline 2nd Lag & & $\begin{array}{c}.103 \\
(.003)^{* * *}\end{array}$ & $\begin{array}{c}.082 \\
(.004)^{* * *}\end{array}$ \\
\hline 3rd Lag & & & $\begin{array}{c}.084 \\
(.004)^{* * *}\end{array}$ \\
\hline Ocean Charge $_{i j t}$ & $\begin{array}{c}-.045 \\
(.003)^{* * * *}\end{array}$ & $\begin{array}{c}-.057 \\
(.004)^{* * * *}\end{array}$ & $\begin{array}{c}-.062 \\
(.005)^{* * * *}\end{array}$ \\
\hline $\mathrm{P}_{i j t}$ & $\begin{array}{c}.624 \\
(.003)^{* * * *}\end{array}$ & $\begin{array}{c}.638 \\
(.003)^{* * *}\end{array}$ & $\begin{array}{c}.644 \\
(.004)^{* * *}\end{array}$ \\
\hline Count $_{i j t}$ & $\begin{array}{c}.445 \\
(.002)^{* * *}\end{array}$ & $\begin{array}{c}.467 \\
(.002)^{* * *}\end{array}$ & $\begin{array}{c}.481 \\
(.003)^{* * *}\end{array}$ \\
\hline $\mathrm{R}_{j t}$ & $\begin{array}{l}-1.076 \\
(.038)^{* * *}\end{array}$ & $\begin{array}{l}-1.158 \\
(.045)^{* * *}\end{array}$ & $\begin{array}{l}-1.207 \\
(.051)^{* * * *}\end{array}$ \\
\hline Pipeline Cost $_{j t}$ & $\begin{array}{c}.347 \\
(.012)^{* * * *}\end{array}$ & $\begin{array}{c}.372 \\
(.015)^{* * * *}\end{array}$ & $\begin{array}{c}.385 \\
(.017)^{* * * *}\end{array}$ \\
\hline $\operatorname{AvDays}_{j t}$ & $\begin{array}{c}-.805 \\
(.026)^{* * *}\end{array}$ & $\begin{array}{c}-.842 \\
(.031)^{* * *}\end{array}$ & $\begin{array}{c}-.845 \\
(.036)^{* * *}\end{array}$ \\
\hline $\mathrm{V}(\mathrm{e})_{j t}$ & $\begin{array}{l}.022 \\
(.001)^{* * *}\end{array}$ & $\begin{array}{l}.018 \\
(.001)^{* * *}\end{array}$ & $\begin{array}{c}.015 \\
(.001)^{* * *}\end{array}$ \\
\hline $\bar{N}$ & 759800 & 585911 & 461958 \\
\hline Pseudo $R^{2}$ & 0.43 & 0.43 & 0.43 \\
\hline$C h i^{2}$ & 120232.50 & 86979.99 & 64514.75 \\
\hline
\end{tabular}

Note: Dependent Variable: Indicator $I_{i j t}=1$ if air shipment is strictly greater than zero and $I_{i j t}=0$ otherwise. All independent variables are in natural logs. Specification include a year specific effect. Robust standard errors in clustered by country in parenthesis. 
Table 4: Base Specifications

\begin{tabular}{|c|c|c|c|c|}
\hline & $\begin{array}{l}\text { OLS } \\
(1)\end{array}$ & $\begin{array}{l}\mathrm{FE} \\
(2)\end{array}$ & $\begin{array}{l}\text { OLS } \\
(3) \\
\end{array}$ & $\begin{array}{l}\mathrm{FE} \\
(4) \\
\end{array}$ \\
\hline Price Volatility: $\mathrm{V}(\mathrm{p})_{i j t}$ & $\begin{array}{c}.168 \\
(.031)^{* * *}\end{array}$ & $\begin{array}{c}.033 \\
(.011)^{* * *}\end{array}$ & $\begin{array}{c}.167 \\
(.010)^{* * *}\end{array}$ & $\begin{array}{c}.091 \\
(.011)^{* * *}\end{array}$ \\
\hline 1st Lag & $\begin{array}{c}.135 \\
(.016)^{* * *}\end{array}$ & $\begin{array}{c}.074 \\
(.006)^{* * *}\end{array}$ & $\begin{array}{c}.118 \\
(.006)^{* * *}\end{array}$ & $\begin{array}{c}.074 \\
(.004)^{* * *}\end{array}$ \\
\hline 2nd Lag & $\begin{array}{c}.084 \\
(.009)^{* * *}\end{array}$ & $\begin{array}{c}.038 \\
(.008)^{* * *}\end{array}$ & $\begin{array}{c}.065 \\
(.006)^{* * *}\end{array}$ & $\begin{array}{c}.031 \\
(.007)^{* * *}\end{array}$ \\
\hline 3rd Lag & $\begin{array}{c}.073 \\
(.008)^{* * *}\end{array}$ & $\begin{array}{c}.027 \\
(.004)^{* * *}\end{array}$ & $\begin{array}{c}.054 \\
(.004)^{* * *}\end{array}$ & $\begin{array}{c}.021 \\
(.004)^{* * *}\end{array}$ \\
\hline 4th Lag & $\begin{array}{c}.075 \\
(.010)^{* * *}\end{array}$ & $\begin{array}{c}.019 \\
(.005)^{* * *}\end{array}$ & $\begin{array}{c}.043 \\
(.007)^{* * *}\end{array}$ & $\begin{array}{l}.008 \\
(.005)\end{array}$ \\
\hline Air Charge $_{i j t}$ & $\begin{array}{l}-.753 \\
(.030)^{* * *}\end{array}$ & $\begin{array}{l}-.654 \\
(.013)^{* * *}\end{array}$ & $\begin{array}{l}-1.000 \\
(.038)^{* * *}\end{array}$ & $\begin{array}{c}-.719 \\
(.019)^{* * *}\end{array}$ \\
\hline Ocean Charge $_{i j t}$ & $\begin{array}{l}1.092 \\
(.058)^{* * *}\end{array}$ & $\begin{array}{c}.450 \\
(.020)^{* * *}\end{array}$ & $\begin{array}{c}.328 \\
(.021)^{* * *}\end{array}$ & $\begin{array}{c}.129 \\
(.009)^{* * *}\end{array}$ \\
\hline $\mathrm{P}_{i j t}$ & & & $\begin{array}{l}1.051 \\
(.029)^{* * *}\end{array}$ & $\begin{array}{c}1.036 \\
(.011)^{* * *}\end{array}$ \\
\hline Count $_{i j t}$ & & & $\begin{array}{c}.043 \\
(.013)^{* * *}\end{array}$ & $\begin{array}{l}.023 \\
(.018)\end{array}$ \\
\hline $\mathrm{R}_{j t}$ & & & $\begin{array}{l}-.895 \\
(.266)^{* * *}\end{array}$ & $\begin{array}{r}-.170 \\
(.167)\end{array}$ \\
\hline Pipeline Cost $_{j t}$ & & & $\begin{array}{c}.299 \\
(.088)^{* * *}\end{array}$ & $\begin{array}{l}.055 \\
(.051)\end{array}$ \\
\hline $\mathrm{V}(\mathrm{e})_{j t}$ & & & $\begin{array}{l}.028 \\
(.017)\end{array}$ & $\begin{array}{r}-.015 \\
(.012)\end{array}$ \\
\hline $\bar{N}$ & 201297 & 201297 & 201297 & 201297 \\
\hline$R^{2}$ & .24 & .129 & .512 & .265 \\
\hline$F$ & 560.664 & 1348.5 & 2120.412 & 4557.043 \\
\hline
\end{tabular}

Note: Dependent Variable: Log of Airshare. All independent variables are in natural logs. Robust standard errors clustered by country in parenthesis. Specifications include a year specific effect. 
Table 5: Alternative Measures of Volatility

\begin{tabular}{|c|c|c|c|c|c|}
\hline & & $\begin{array}{l}\mathrm{FE} \\
(1)\end{array}$ & $\begin{array}{l}\text { FE } \\
(2)\end{array}$ & $\begin{array}{l}\mathrm{FE} \\
(3)\end{array}$ & $\begin{array}{l}\overline{F E} \\
(4)\end{array}$ \\
\hline Current & & $\begin{array}{l}-.093 \\
(.016)^{* * *}\end{array}$ & & & \\
\hline 1st Lag & Quantity & $\begin{array}{l}.147 \\
(.011)^{* * *}\end{array}$ & & & \\
\hline 2nd Lag & $\begin{array}{l}\text { Volatillty } \\
\mathrm{V}(\mathrm{Q})_{i j t}\end{array}$ & $\begin{array}{c}.074 \\
(.012)^{* * *}\end{array}$ & & & \\
\hline 3rd Lag & & $\begin{array}{l}.041 \\
(.006)^{* * *}\end{array}$ & & & \\
\hline Current & & & $\begin{array}{c}.051 \\
(.006)^{* * *}\end{array}$ & & \\
\hline 1st Lag & $\begin{array}{l}\text { Ocean } \\
\text { Price }\end{array}$ & & $\begin{array}{c}.068 \\
(.007)^{* * *}\end{array}$ & & \\
\hline 2nd Lag & Volatility & & $\begin{array}{l}.038 \\
(.007)^{* * *}\end{array}$ & & \\
\hline 3rd Lag & $V(\mathrm{po})_{i j t}$ & & $\begin{array}{l}.027 \\
(.004)^{* * *}\end{array}$ & & \\
\hline Current & Price & & & $\begin{array}{c}.026 \\
(.012)^{* *}\end{array}$ & \\
\hline 1st Lag & Volatility: & & & $\begin{array}{l}.105 \\
(.008)^{* * * *}\end{array}$ & \\
\hline 2nd Lag & $\begin{array}{c}\text { Seasonality } \\
\text { Adjusted }\end{array}$ & & & $\begin{array}{c}.059 \\
(.010)^{* * *}\end{array}$ & \\
\hline 3rd Lag & Prices & & & $\begin{array}{c}.038 \\
(.006)^{* * *}\end{array}$ & \\
\hline Current & $\begin{array}{c}\text { Price } \\
\text { Potilin. }\end{array}$ & & & & $\begin{array}{l}.029 \\
(.012)^{* *}\end{array}$ \\
\hline 1st Lag & Seasonality & & & & $\begin{array}{l}.104 \\
\left(.0088^{* * * *}\right.\end{array}$ \\
\hline 2nd Lag & $\begin{array}{l}\text { and Lag } \\
\text { Adiusted }\end{array}$ & & & & $\begin{array}{c}.056 \\
(.010)^{* * *}\end{array}$ \\
\hline 3rd Lag & $\begin{array}{c}\text { Adjusted } \\
\text { Prices }\end{array}$ & & & & $\begin{array}{c}.037 \\
(.005)^{* * *}\end{array}$ \\
\hline$\overline{\text { Air Charge }}{ }_{i j t}$ & & $\begin{array}{l}-.651 \\
(.013)^{* * *}\end{array}$ & $\begin{array}{l}-.665 \\
(.016)^{* * *}\end{array}$ & $\begin{array}{l}-.654 \\
. .013)^{* * *}\end{array}$ & $\begin{array}{c}-.653 \\
(.012)^{* * *}\end{array}$ \\
\hline Ocean Charge $_{i j t}$ & & $\begin{array}{c}.433 \\
(.020)^{* * *}\end{array}$ & $\begin{array}{c}.527 \\
(.022)^{* * *}\end{array}$ & $\begin{array}{c}.450 \\
(.020)^{* * *}\end{array}$ & $\begin{array}{c}.451 \\
(.021)^{* * *}\end{array}$ \\
\hline $\bar{N}$ & & 201283 & 181011 & 201297 & 201182 \\
\hline$R^{2}$ & & .131 & .137 & .129 & .129 \\
\hline$F$ & & 1419.829 & 940.006 & 1066.12 & 1039.115 \\
\hline
\end{tabular}

Note: Dependent Variable: Log of Airshare. All independent variables are in natural logs. Robust standard errors clustered by country in parenthesis. Specifications include a year specific effect. 
Table 6: Impacts of Lagged Dependent Variables

\begin{tabular}{|c|c|c|}
\hline & $\begin{array}{c}\text { FD-2SLS } \\
(1)\end{array}$ & $\begin{array}{c}\text { FD-2SLS } \\
(2)\end{array}$ \\
\hline $\bar{\Delta}$ Lag of Airshare $\left(S_{i j t-1}\right)$ & $\begin{array}{l}.109^{\dagger} \\
(.008)^{* * *}\end{array}$ & $\begin{array}{c}.089^{\dagger} \\
(.010)^{* * *}\end{array}$ \\
\hline 2nd Lag & & $\begin{array}{r}-.008 \\
(.005)\end{array}$ \\
\hline$\Delta$ Price Volatility $\left(\mathrm{V}(\mathrm{p})_{i j t}\right)$ & $\begin{array}{l}.069 \\
(.009)^{* * *}\end{array}$ & $\begin{array}{c}.069 \\
(.009)^{* * *}\end{array}$ \\
\hline 1st Lag & $\begin{array}{l}.064 \\
(.003)^{* * * *}\end{array}$ & $\begin{array}{l}.065 \\
(.003)^{* * *}\end{array}$ \\
\hline 2nd Lag & $\begin{array}{l}.016 \\
(.005)^{* * * *}\end{array}$ & $\begin{array}{l}.019 \\
(.006)^{* * *}\end{array}$ \\
\hline 3rd Lag & $\begin{array}{l}.010 \\
(.005)^{*}\end{array}$ & $\begin{array}{l}.014 \\
(.005)^{* * *}\end{array}$ \\
\hline$\Delta$ Air Charge $_{i j t}$ & $\begin{array}{l}-.719 \\
(.019)^{* * *}\end{array}$ & $\begin{array}{l}-.713 \\
(.019)^{* * *}\end{array}$ \\
\hline$\Delta{\text { Ocean } \text { Charge }_{i j t}}$ & $\begin{array}{l}.113 \\
(.010)^{* * *}\end{array}$ & $\begin{array}{l}.112 \\
(.010)^{* * *}\end{array}$ \\
\hline$\Delta \mathrm{P}_{i j t}$ & $\begin{array}{l}1.031 \\
(.010)^{* * *}\end{array}$ & $\begin{array}{l}1.024 \\
(.011)^{* * *}\end{array}$ \\
\hline$\Delta$ Count $_{i j t}$ & $\begin{array}{c}.071 \\
(.015)^{* * *}\end{array}$ & $\begin{array}{l}.071 \\
(.015)^{* * *}\end{array}$ \\
\hline$\Delta \mathrm{R}_{j t}$ & $\begin{array}{l}-.429 \\
(.143)^{* * * *}\end{array}$ & $\begin{array}{l}-.421 \\
(.139)^{* * *}\end{array}$ \\
\hline$\Delta$ Pipeline Cost $_{j t}$ & $\begin{array}{l}.140 \\
(.047)^{* * * *}\end{array}$ & $\begin{array}{l}.137 \\
(.045)^{* * *}\end{array}$ \\
\hline$\Delta \mathrm{V}(\mathrm{e})_{j t}$ & $\begin{array}{l}-.031 \\
(.014)^{* *}\end{array}$ & $\begin{array}{l}-.030 \\
(.014)^{* *}\end{array}$ \\
\hline $\bar{N}$ & 160549 & 160549 \\
\hline$F$ & 3599.823 & 3247.67 \\
\hline
\end{tabular}

Note: FD-2SLS(1-2) First difference 2 stage least squares estimation with robust standard errors clustered by country. Dependent variable: First difference of the log air share. $\Delta$ : Log-difference operator. $\dagger$ : Instrumented variables. We report the first stage $R^{2}$ in the order as the instrumented variables appear in the table from top to bottom. Column(1) instruments using $\Delta S_{i j t-2}\left(R^{2}=0.19\right)$. Column(2) instruments using $\Delta S_{i j t-3}\left(R^{2}=0.24\right)$. All specifications include a year fixed effect. Robust standard errors in parentheses. 
Table 7: Endogeneity of Price Volatility

\begin{tabular}{lcccc}
\hline \hline & $\begin{array}{c}\text { FD-2SLS } \\
(1)\end{array}$ & $\begin{array}{c}\text { FD-2SLS } \\
(2)\end{array}$ & $\begin{array}{c}\text { FD-2SLS } \\
(3)\end{array}$ & $\begin{array}{c}\text { FD-2SLS } \\
(4)\end{array}$ \\
\hline$\Delta$ Lag Air Share $\left(S_{i j t-1}\right)$ & $.113 \dagger$ & $.113 \dagger$ & $.113 \dagger$ & $.112 \dagger$ \\
& $(.008)^{* * *}$ & $(.008)^{* * *}$ & $(.008)^{* * *}$ & $(.008)^{* * *}$ \\
$\Delta$ Price Volatility: $\mathrm{V}(\mathrm{p})_{i j t}$ & .044 & $.067 \dagger$ & $-.100 \dagger$ & \\
& $(.014)^{* * *}$ & $(.056)$ & $(.245)$ & \\
$\Delta$ 1st Lag & .064 & .077 & $.111 \dagger$ & .091 \\
& $(.003)^{* * *}$ & $(.025)^{* * *}$ & $(.054)^{* *}$ & $(.036)^{* *}$ \\
$\Delta$ 2nd Lag & .019 & .026 & .039 & .032 \\
& $(.007)^{* * *}$ & $(.019)$ & $(.027)$ & $(.023)$ \\
$\Delta$ 3rd Lag & .013 & .017 & .022 & .019 \\
& $(.005)^{* *}$ & $(.009)^{*}$ & $(.013)^{*}$ & $(.011)^{*}$ \\
$\Delta$ Air Charge ${ }_{i j t}$ & -.697 & -.698 & -.692 & -.696 \\
& $(.016)^{* * *}$ & $(.016)^{* * *}$ & $(.017)^{* * *}$ & $(.016)^{* * *}$ \\
$\Delta$ Ocean Charge $_{i j t}$ & .244 & .244 & .236 & .240 \\
& $(.040)^{* * *}$ & $(.039)^{* * *}$ & $(.040)^{* * *}$ & $(.040)^{* * *}$ \\
$\Delta$ P $_{i j t}$ & $.586 \dagger$ & $.591 \dagger$ & $.570 \dagger$ & $.585 \dagger$ \\
$\Delta$ Count $_{i j t}$ & $(.145)^{* * *}$ & $(.147)^{* * *}$ & $(.146)^{* * *}$ & $(.139)^{* * *}$ \\
& .059 & .063 & .032 & .051 \\
$\Delta$ R $_{j t}$ & $(.018)^{* * *}$ & $(.023)^{* * *}$ & $(.046)$ & $(.017)^{* * *}$ \\
& -.400 & -.400 & -.404 & -.402 \\
$\Delta$ Pipeline Cost $_{j t}$ & $(.139)^{* * *}$ & $(.139)^{* * *}$ & $(.138)^{* * *}$ & $(.139)^{* * *}$ \\
$\Delta$ V $\left.^{*}\right)_{j t}$ & .132 & .132 & .134 & .133 \\
& $(.045)^{* * *}$ & $(.045)^{* * *}$ & $(.045)^{* * *}$ & $(.045)^{* * *}$ \\
$N$ & -.031 & -.031 & -.031 & -.031 \\
$F$ & $(.013)^{* *}$ & $(.013)^{* *}$ & $(.013)^{* *}$ & $(.013)^{* *}$ \\
\hline \hline
\end{tabular}

Note: FD-2SLS(1-2) First difference 2 stage least squares estimation with robust standard errors clustered by country. Dependent variable: First difference of the log air share, $S_{i j t} . \Delta$ : First difference operator. All variables are in logs. $\dagger:$ Instrumented variables. We report the first stage $R^{2}$ in the order as the instrumented variables appear in the table from top to bottom. Column(1) instruments using $\Delta S_{i j t-2}, \Delta S_{i j t-3}$, $\Delta p_{i j t-2}$. The first stage $R^{2}$ are 0.23 and 0.18. Column(2) instruments using $\Delta S_{i j t-2}$, $\Delta S_{i j t-3}, \Delta p_{i j t-2}, \Delta s d p_{i j t-4}, s d p_{i j t-2}$. The first stage $R^{2}$ are $0.23,0.3$ and 0.17. Column(3) and Column(4) instrument using $\Delta S_{i j t-2}, \Delta S_{i j t-3}, \Delta p_{i j t-2}, \Delta s d p_{i j t-4}, s d p_{i j t-2}$. The first stage $R^{2}$ are $.23, .03, .28, .17$ and $.23, .28, .17$ respectively. All specifications include a year fixed effect. The standard errors are reported in parentheses. 


\section{APPENDIX}

\section{A-1. Demand, Uncertainty and Costs}

The model in the main body of the paper employs linear demand and a uniform distribution for the demand shock. In this section we show that most of our results are robust to more general forms of demand and more general shock processes. A monopolist faces the inverse demand $P=\epsilon(h, x) p(Q)$ on the foreign market, where the partial derivatives $p^{\prime}(Q)=\frac{\partial p(Q)}{\partial Q}<0$ and $p^{\prime \prime}(Q)=\frac{\partial^{2} p(Q)}{\partial^{2} Q} \leq 0 .^{26} \quad$ As before, let the quantity shipped over the ocean and air be $q^{o}$ and $q^{a}$ such that $Q=q^{o}+q^{a}$. Ocean shipments take one period to arrive and must be set before the demand uncertainty is resolved. Air shipments arrive immediately and are set after the shock $\epsilon(h, x)$ is known. The rates $f^{a}$ and $f^{o}$ determine the constant marginal cost of producing and then shipping a unit via air and ocean transport, $f^{a}>f^{o}>0$.

The key comparative static results of interest concern the share of air shipping in final sales and how they respond to changes in ocean and air shipping prices, and to changes in the variance of the demand shocks facing the firm. With a uniform distribution on $\epsilon(h, x)$ as in the model in Section 2, we can simply describe the variance of demand shocks in terms of the bounds $(1-z, 1+z)$ on the shock. This comparative static can then be interpreted in the empirics in terms of differences across products or changes over time for a given product. For a more general density, we consider transformations of that density that result in changes in the mean preserving spread. (The transformation must be mean preserving because otherwise changes in the probability density affect the share of air shipping through changes in both the first and second moments, and we wish to isolate only those changes arising from the second moment.) Let $x$ be a random process distributed according to the continuous probability density $g(x)$ with mean $\mu$ and variance $\sigma_{x}^{2}$ such that $\int_{\mu-z}^{\mu+z} g(x)=1$ and $\mu-z>0$. We then consider $\epsilon(h, x)=\mu+h(x-\mu)$ as a mean preserving transformation of $x .^{27}$ Note that the expected value $E(\mu+h(x-\mu))=\mu$ and the variance $\operatorname{Var}(\mu+h(x-\mu))=h^{2} \sigma_{x}^{2}$ for

\footnotetext{
${ }^{26}$ We write $p^{\prime}=p^{\prime}(\cdot)$ and $p^{\prime \prime}=p^{\prime \prime}(\cdot)$ when the dependence on $Q$ is understood or not of consequence for the argument.

${ }^{27}$ From here on we notate the shock by $\epsilon$ if the relationship on $h$ or $x$ is understood or does not have any consequence for the argument.
} 
$h>0$. In the case of $h=1$, the demand shock $\epsilon(h, x)$ is distributed identically to $x$. Changes in $h$ affect the variance of demand but not the mean, allowing us to provide clean comparative statics on $h$.

\section{A-1.1. Second Period}

In the second period the monopolist's objective is to maximize

$$
L=\epsilon p\left(q^{o}+q^{a}\right) \cdot\left(q^{o}+q^{a}\right)-f^{a} q^{a}-f^{o} q^{o}+\lambda q^{a}
$$

w.r.t. to the air quantity $q^{a}$ taking the shock $\epsilon$ and the first period ocean shipment as given. The multiplier $\lambda$ is the slackness parameter on the constraint $q^{a} \geq 0$. The first order conditions are

$$
\begin{aligned}
& L_{q^{a}}=\epsilon\left(p^{\prime}\left(q^{o}+q^{a}\right)+p\left(q^{o}+q^{a}\right)\right)-f^{a}-\lambda=0 \\
& L_{\lambda}=q^{a} \geq 0, \lambda \geq 0, \lambda q^{a}=0 .
\end{aligned}
$$

Then, for $\lambda=0$, the optimal air shipment decreases in the level of the first period ocean shipment. Apply the implicit function theorem to obtain ${ }^{28}$

$$
\frac{d q^{a}}{d q^{o}}=-\frac{L_{q^{a} q^{o}}}{L_{q^{a} q^{a}}}=-\frac{\epsilon p^{\prime \prime}+2 \epsilon p^{\prime}}{\epsilon p^{\prime \prime}+2 \epsilon p^{\prime}}=-1
$$

This implies there is a one to one relationship between the air and ocean quantities.

For an interior solution of $q^{a}$ the air quantity increases in the level of the shock. To see this apply the implicit function theorem to obtain

$$
\frac{d q^{a}}{d \epsilon}=-\frac{L_{q^{a} \epsilon}}{L_{q^{a} q^{a}}}=-\frac{p^{\prime}+p}{\epsilon p^{\prime \prime}+2 \epsilon p^{\prime}}>0
$$

The numerator must be positive, because if the numerator would be negative, then the first order condition would be negative. Given the assumptions on demand it is easy to see that the denominator is negative, which is also the second order condition. This implies that $q^{a}$ is strictly increasing in $\epsilon$. Then, equations (A-3) and (A-4) imply that

\footnotetext{
${ }^{28}$ Here and throughout we assume that the demand and density functions are such that the profit and expected profit functions are sufficiently differentiable.
} 
for a sufficiently large ocean shipment and a sufficiently low realization of the shock the firm may set air shipment equal to zero. To find the cutoff level for zero air shipment $\epsilon^{*}$, evaluate the first order condition at $q^{a}=0$ and solve for $\epsilon$ to obtain ${ }^{29}$

$$
\epsilon^{*}=\left(\mu+h\left(x^{*}-\mu\right)\right)=\frac{f^{a}}{p^{\prime}\left(q^{o}\right)+p\left(q^{o}\right)}
$$

Note that $\epsilon^{*}$ increases in the air freight rate $f^{a}$ and increases in the first period ocean shipment, as the denominator decreases in $q^{o} \cdot{ }^{30}$ Note that $\epsilon^{*}$ pins down a unique value of $x^{*}$ and it is useful for what follows to specify the zero air shipment threshold in terms of $x^{*}$ such that

$$
x^{*}\left(f^{a}, q^{o}, h\right)=\frac{f^{a}}{h\left[p^{\prime}\left(q^{o}\right)+p\left(q^{o}\right)\right]}-\frac{\mu}{h}+\mu .^{31} .
$$

The first order condition (A-1) defines the second period optimal air shipment as a function of the first period ocean shipment and the realization of the shock, $q^{a}\left(q^{o}, x\right)$. Recognizing the constraint on $q^{a}$, substitute $q^{a}\left(q^{o}, x\right)$ into the firm's profits to obtain the firms second period profit for a given realization of $x$,

$$
\left\{\begin{array}{cc}
\pi_{1}\left(q^{o}, q^{a}\left(q^{o}, x\right) ; x\right)=(\mu+h(x-\mu)) p\left(q^{o}+q^{a}\left(q^{o}, x\right)\right) & \\
\left(q^{o}+q^{a}\left(q^{o}, x\right)\right)-f^{a} q^{a}\left(q^{o}, x\right)-f^{o} q^{o} & \text { if } x>x^{*} \\
\pi_{2}\left(q^{o}, 0 ; x\right)=(\mu+h(x-\mu)) p\left(q^{o}\right) \cdot q^{o}-f^{o} q^{o} & \text { if } x \leq x^{*}
\end{array}\right.
$$

Now take the expectation over all realizations of $x$ to obtain the expected first period profits

$$
E\left(\Pi\left(q^{o}\right)\right)=\int_{\mu-z}^{x^{*}} \pi_{2}\left(q^{o}, 0 ; x\right) g(x) d x+\int_{x^{*}}^{\mu+z} \pi_{1}\left(q^{o}, q^{a}\left(q^{o}, x\right) ; x\right) g(x) d x .
$$

\footnotetext{
${ }^{29}$ This also implies the possibility that for certain distribution, cost and demand parameters there are no realizations of $\epsilon$ that induce an air shipment (see Figure $\mathrm{xx}$ for $z<z^{*}$ ). Since this cutoff depends on the particular demand and cost structure, we limit the following discussion to interior solutions where at least for some realization of the shock air shipment is optimal.

${ }^{30}$ For what follows we assume that the parameters are such that $x^{*}$ lies within the upper and lower bounds of the distribution. In the case of the a linear demand and uniform distribution the theory section in the main body of the paper shows that this is not necessarily satisfied.

${ }^{31}$ Again, if the relationship of $x^{*}$ and $f^{a}, q^{o}, h$ is understood or not of consequence we write $x^{*}$.
} 
Take the first order condition with respect to $q^{o}$ to obtain

$$
\begin{aligned}
\frac{\partial E\left(\Pi\left(q^{o}\right)\right)}{\partial q^{o}}= & \int_{\mu-z}^{x^{*}} \frac{\partial \pi_{2}\left(q^{o}, 0 ; x\right)}{\partial q^{o}} g(x) d x+\frac{\partial x^{*}}{\partial q^{o}} \pi_{2}\left(q^{o}, 0 ; x^{*}\right) g\left(x^{*}\right)+ \\
& \int_{x^{*}}^{\mu+z} \frac{\partial \pi_{1}\left(q^{o}, q^{a}\left(q^{o}, x\right) ; x\right)}{\partial q^{o}} g(x) d x-\frac{\partial x^{*}}{\partial q^{o}} \pi_{1}\left(q^{o}, q^{a}\left(q^{o}, x^{*}\right) ; x^{*}\right) g\left(x^{*}\right)
\end{aligned}
$$

Note that evaluated at the zero air shipment threshold $\frac{\partial x^{*}}{\partial q^{o}} \pi_{1}\left(q^{o}, q^{a}\left(q^{o}, x^{*}\right) ; x^{*}\right) g\left(x^{*}\right)=$ $\frac{\partial x^{*}}{\partial q^{o}} \pi_{2}\left(q^{o}, 0 ; x^{*}\right) g\left(x^{*}\right)$, because $q^{a}\left(q^{o}, x^{*}\right)=0$, and (A-9) simplifies to

$$
\begin{aligned}
\frac{\partial E\left(\Pi\left(q^{o}\right)\right)}{\partial q^{o}}=M\left(q^{o}, f^{o}, f^{a}, h\right) & =\int_{\mu-z}^{x^{*}} \frac{\partial \pi_{2}\left(q^{o}, 0 ; x\right)}{\partial q^{o}} g(x) d x \\
& +\int_{x^{*}}^{\mu+z} \frac{\partial \pi_{1}\left(q^{o}, q^{a}\left(q^{o}, x\right) ; x\right)}{\partial q^{o}} g(x) d x
\end{aligned}
$$

Substitute the appropriate derivatives of (A-7) into (A-10) to obtain

$$
\begin{aligned}
& M\left(q^{o}, f^{o}, f^{a}, h\right)=\int_{\mu-z}^{x^{*}}\left([\epsilon(h, x)]\left[p^{\prime}\left(q^{o}\right) \cdot q^{o}+p\left(q^{o}\right)\right]-f^{o}\right) g(x) d x+ \\
& \int_{x^{*}}^{\mu+z}\left(\epsilon(h, x)\left[p^{\prime}\left(q^{o}+q^{a}\left(q^{o}, x\right)\right) \cdot\left(1+\frac{\partial q^{a}\left(q^{o}, x\right)}{\partial q^{o}}\right) \cdot\left(q^{o}+q^{a}\left(q^{o}, x\right)\right)\right]\right) g(x) d x+ \\
& \int_{x^{*}}^{\mu+z}\left(\epsilon(h, x)\left[p\left(q^{o}+q^{a}\left(q^{o}, x\right)\right) \cdot\left(1+\frac{\partial q^{a}\left(q^{o}, x\right)}{\partial q^{o}}\right)\right]-f^{a} \frac{\partial q^{a}\left(q^{o}, x\right)}{\partial q^{o}}-f^{o}\right) g(x) d x
\end{aligned}
$$

Now substitute the result $\frac{d q^{a}}{d q^{o}}=-1$ from (A-3) into (A-11) to simplify further to obtain

$$
\begin{array}{r}
M\left(q^{o}, f^{o}, f^{a}, h\right)=\int_{\mu-z}^{x^{*}}\left([\epsilon(h, x)]\left[p^{\prime}\left(q^{o}\right) \cdot q^{o}+p\left(q^{o}\right)\right]-f^{o}\right) g(x) d x+ \\
\int_{x^{*}}^{\mu+z}\left(f^{a}-f^{o}\right) g(x) d x
\end{array}
$$

With (A-12) at hand we can show the impact of a change in the freight rates and variance of the shock on the ocean quantity evaluated at an interior solution $q^{o}>0$ and some first period probability of air transport $0<\operatorname{Prob}\left(x>x^{*}\right)<1$.

First, apply the implicit function theorem to obtain 


$$
\frac{d q^{o}}{d f^{o}}=-\frac{\frac{\partial M(\cdot)}{\partial f^{\circ}}}{\frac{\partial M(\cdot)}{\partial q^{\circ}}}=-\frac{\int_{\mu-z}^{x^{*}}-g(x) d x+\int_{x^{*}}^{\mu+z}-g(x) d x}{S O C}=\frac{1}{S O C}<0,
$$

because the second order condition $S O C<0$ in optimum.

Second, apply the implicit function theorem to obtain

$$
\frac{d q^{o}}{d f^{a}}=-\frac{\frac{\partial M(\cdot)}{\partial f^{a}}}{\frac{\partial M(\cdot)}{\partial q^{\circ}}}=-\frac{\int_{x^{*}}^{\mu+z} g(x) d x}{S O C}>0 .
$$

This expression results because the derivative of the bound $x^{*}$ with respect to $f^{a}$ is equal to the second period first order condition evaluated at $x^{*}$ which is equal to zero.

Third, apply the implicit function theorem to obtain

$$
\frac{d q^{o}}{d h}=-\frac{\frac{\partial M(\cdot)}{\partial h}}{\frac{\partial M(\cdot)}{\partial q^{o}}}<0
$$

Taking the appropriate derivative we obtain

$$
\begin{aligned}
\frac{\partial M(\cdot)}{\partial h}= & \int_{\mu-z}^{x^{*}}\left((x-\mu)\left(p^{\prime}\left(q^{o}\right)\right) q^{o}+(x-\mu) p\left(q^{o}\right)\right) g(x) d x+ \\
& \left(\frac{\partial x^{*}}{\partial h}\right)\left(\left(\mu+h\left(x^{*}-\mu\right)\right)\left[\left(p^{\prime}\left(q^{o}\right)\right) q^{o}+p\left(q^{o}\right)\right]-f^{a}\right) g\left(x^{*}\right) .
\end{aligned}
$$

Note that the middle term in (A-17) is equal to the first order condition of the second period maximization problem evaluated at $x^{*}$, or equation (A-1) evaluated at the level of the shock such that $q^{a}$ is just equal to zero. This implies

$$
\begin{aligned}
\frac{d q^{o}}{d h} & =-\frac{\int_{\mu-z}^{x^{*}}\left((x-\mu)\left(p^{\prime}\left(q^{o}\right)\right) q^{o}+(x-\mu) p\left(q^{o}\right)\right) g(x) d x}{S O C} \\
& =-\frac{\left(\left(p^{\prime}\left(q^{o}\right)\right) q^{o}+p\left(q^{o}\right)\right) \int_{\mu-z}^{x^{*}}(x-\mu) g(x) d x}{S O C}<0
\end{aligned}
$$

Note that $p^{\prime}\left(q^{o}\right) q^{o}+p\left(q^{o}\right)>0$. To see this note that if the firm expects to get the highest shock with certainty, then it will ship an ocean quantity such that the marginal revenue at the highest shock equals the marginal ocean transport cost, $(\mu+z)\left(p^{\prime} \cdot q^{o}+\right.$ $p)=f^{o}$. This implies that even at the largest possible quantity a firm would ever ship in our set up, the firm ships an ocean quantity such that $p^{\prime} q^{o}+p>0$. 
Then,

$$
\frac{d q^{o}}{d h}<0 \Leftrightarrow \int_{\mu-z}^{x^{*}}(x-\mu) g(x) d x<0 .
$$

To show that $A=\int_{\mu-z}^{x^{*}}(x-\mu) g(x) d x<0$ note that

$$
\underbrace{\int_{\mu-z}^{x^{*}}(x-\mu) g(x) d x}_{A}+\underbrace{\int_{x^{*}}^{\mu+z}(x-\mu) g(x) d x}_{B}=0 .
$$

For this condition to hold, $A$ and $B$ can't both be negative or positive at the same time. This implies $A \geq 0 \Leftrightarrow B \leq 0$. By contradiction, suppose that $B \leq 0$. $B \leq 0$ iff $x^{*}-\mu<0$. But if $x^{*}-\mu<0$ then $x-\mu<0$ for all $x \leq x^{*}$, which implies that $A<0$ because $g(x) \geq 0$ for all $x$ in its support. This implies that if $B<0$, then $A<0$ and (A-21) can't be equal to zero. It follows that $B>0, A<0$ and

$$
\frac{d q^{o}}{d h}<0
$$

Theorem 1. For an interior solution $q^{\circ}>0$ and level of the shock $\epsilon$ such that the air quantity is greater or equal to zero, the share of air shipments in the total quantity:

1. Increases as the variance of the shock, $h$, increases

2. Increases as the ocean transport cost, $f^{\circ}$, increases

3. Decreases as the air transport cost, $f^{a}$, increases

4. Increases in the realization of the shock $\epsilon$

Proof. Equation (A-1) implicitly defines the optimal second period air shipment. Note that the air freight rate $f^{a}$ and the level of the shock $\epsilon$ enter this relationship directly, while the ocean freight rate and variance parameter $h$ work entirely through the first period ocean shipment. To show the first two claims of the proposition, equation (A-3), shows that the optimal air shipment decreases in the ocean quantity for a given level of the shock. Equations (A-18) and (A-13) show that the ocean quantity decreases in the variance of the shock and the level of the ocean transport cost. Combined this implies that for a given level of the shock, an increase in the variance or the ocean freight rate lowers the first period ocean shipment, but raises the second period air shipment, which implies that the share of air shipments in the total supply increase. 
To show the third claim of the proposition note that the air freight rate enters the second period first order condition (A-1) directly and working through the optimal ocean quantity. Suppose the air freight rate increases. Evaluated at an interior solution, the direct impact of the air freight rate is negative. By equation (A-14) the indirect effect working through the ocean quantity is also negative; the optimal ocean quantity increases as the air freight rate increases, because the marginal revenue $p^{\prime}\left(q^{o}+q^{a}\right)+$ $p\left(q^{o}+q^{a}\right)$ decreases in the total quantity. At a given level of the shock, both impacts call forth a decreases in the second period air shipment to set the second period first order condition back to zero. Combined these effects imply that at a given level of the shock, an increases in the air freight rate lowers the second period air shipment and raises the first period ocean shipment. This implies that at the given level of the shock, the share of air shipment decreases as the air freight rate increases.

Finally, equation (A-4) says that all else equal, an increase in the shock $\epsilon$ raises the level of the second period air shipment. Note that the first period ocean shipment is predetermined and so the second period shock does not enter the ocean shipment. This implies that all else equal, an increases in $\epsilon$ raises the air quantity while the ocean quantity remains unchanged and the share of air shipments increase as $\epsilon$ increases. 